\title{
Low-Power Sensor Interface with a Switched Inductor Frequency Selective Envelope Detector
}

\author{
Marko Gazivoda *(D) and Vedran Bilas \\ Faculty of Electrical Engineering and Computing, University of Zagreb, 10000 Zagreb, Croatia; \\ vedran.bilas@fer.hr \\ * Correspondence: marko.gazivoda@fer.hr
}

Citation: Gazivoda, M.; Bilas, V. Low-Power Sensor Interface with a Switched Inductor Frequency Selective Envelope Detector. Sensors 2021, 21, 2124. https://doi.org/ $10.3390 / \mathrm{s} 21062124$

Academic Editor: Fabian Khateb

Received: 17 February 2021

Accepted: 16 March 2021

Published: 18 March 2021

Publisher's Note: MDPI stays neutral with regard to jurisdictional claims in published maps and institutional affiliations.

Copyright: (c) 2021 by the authors. Licensee MDPI, Basel, Switzerland. This article is an open access article distributed under the terms and conditions of the Creative Commons Attribution (CC BY) license (https:// creativecommons.org/licenses/by/ $4.0 /)$.

\begin{abstract}
With the growing need to understand our surroundings and improved means of sensor manufacturing, the concept of Internet of Things (IoT) is becoming more interesting. To enable continuous monitoring and event detection by IoT, the development of low power sensors and interfaces is required. In this work we present a novel, switched inductor based acoustic sensor interface featuring a bandpass filter and envelope detector, perform a sensitivity, frequency selectivity, and power consumption analysis of the circuit, and present its design parameters and their qualitative influence on circuit characteristics. We develop a prototype and present experimental characterization of the interface and its operation with input signals up to $20 \mathrm{mV}$ peak-to-peak, at low acoustic frequencies from $100 \mathrm{~Hz}$ to $1 \mathrm{kHz}$. The prototype achieves a sensitivity of approximately $2 \mathrm{mV} / \mathrm{mV}$ in the passband, a four times lower sensitivity in the stopband, and a power consumption of approximately $3.31 \mu \mathrm{W}$. We compare the prototype interface to an interface consisting of an active bandpass filter and a passive voltage doubler using a prerecorded speedboat signal.
\end{abstract}

Keywords: sensor signal conditioning circuit; event detection application; switched inductor filter; weak signal detection

\section{Introduction}

The growing need to understand and manage our surroundings, coupled with advances in sensor technologies and manufacturing processes [1], has led to an increased interest in the concept of Internet of Things (IoT), which envisions sensor networks consisting of hundreds of thousands of small, robust sensor nodes utilized to continuously monitor real-world events and processes [2-4]. Continuous monitoring and event detection emphasize the need for low-power sensors and sensor signal conditioning circuits which enable the node to achieve long life-times, even when powered by small batteries [3-5].

Acoustic sensors present an attractive choice for IoT applications because they generate signals that are rich in information and can be processed using relatively simple hardware [6-8] that powers up the rest of the sensor node only upon detection of an event of interest [4,5], thereby reducing the power consumption of an acoustic sensor node. These wake-up sensor interfaces utilize bandpass filtering, envelope detection, quantization, and some rudimentary form of classification to determine if an event of interest occurred. Implementations of the wake-up interface with an active bandpass filter, diode envelope detector, and microcontroller-based classification are presented in $[9,10]$. The power consumption of the bandpass filter and the envelope detector is reported as $8.25 \mu \mathrm{W}$ in [9] and $20.74 \mu \mathrm{W}$ in [10].

The envelope detector is one of the critical elements in the weak signal front ends in various applications (sensing, communications, energy harvesting) due to its powerconsumption to sensitivity trade-off [11-16]. In [17] we studied the impact of the envelope detector on sensitivity and power consumption of the wake-up sensor interface in the lower audio frequency range. Based on the mechanically switched inductor energy harvester [16], 
in [18] we demonstrated that a piezoelectric energy harvester can be used as a vibration sensor utilizing a mechanically switched inductor driven by the sensed vibrations.

In order to increase the sensitivity of low-power acoustic wake-up sensor interfaces, and at the same time lower their power consumption, in this work we propose a novel approach, utilizing an electrically switched inductor as a replacement for conventionally used bandpass filter and envelope detector functional blocks. Using this approach, inspired by the switched inductor bandpass filter $[19,20]$, and the switched inductor energy harvester $[12,13,16]$, we devise a novel, low-power wake-up sensor interface, operational with weak input signals (around $5 \mathrm{mV}$ ) in the low acoustic frequency range $(100 \mathrm{~Hz}-1 \mathrm{kHz})$ and applicable in low-power always-on acoustic event detectors.

With this work we present several contributions: a novel, frequency-selective, voltageboosting, low-power, weak-signal acoustic sensor interface; a sensitivity, frequency selectivity and power consumption analysis of the circuit; design parameter selection, and their influence on interface characteristics; experimental characterization of a prototype, and its comparison to an interface consisting of an active bandpass filter and a passive voltage doubler.

The rest of this paper is organized as follows: Section 2 presents related circuits and principles of operation. Section 3 shows the proposed interface characteristics and design parameters. Section 4 presents a simulation study of the sensor interface, determining its key design parameters and desired functionality. Section 5 shows the developed prototype and its experimental characterization. In Section 6 a set of design recommendations for interface synthesis are given. Section 7 presents a comparison of the novel sensor interface and interface presented in $[9,18]$ and Section 8 states the concluding remarks of the paper and presents future work.

\section{Related Circuits and Principles of Operation}

The proposed sensor interface utilizes the switched inductor for filtering the sensor signal and extracting and boosting its envelope. This concept was inspired by two previous lines of work, the switched inductor filter and the switched inductor energy harvester.

\subsection{Switched Inductor Filter}

The switched inductor filter (shown in Figure 1a) consisting of a capacitor, $C_{f}$, inductor, $L_{f}$, and two switches $S_{f 1}$ and $S_{f 2}$, is used in power electronics to electrically tune the frequency characteristic of inverter outputs, suppressing unwanted harmonics $[19,20]$. Figure $1 \mathrm{~b}$ shows the electrically tunable frequency characteristic of such a filter and the impact of the switch control function duty cycle as its tuning parameter. The input signal frequency was normalized with regards to the filter central frequency and the output voltage root mean square (RMS) was normalized with regards to the maximal filter output RMS voltage (obtained with the $90 \%$ duty cycle when the input signal frequency was equal to the filter central frequency).

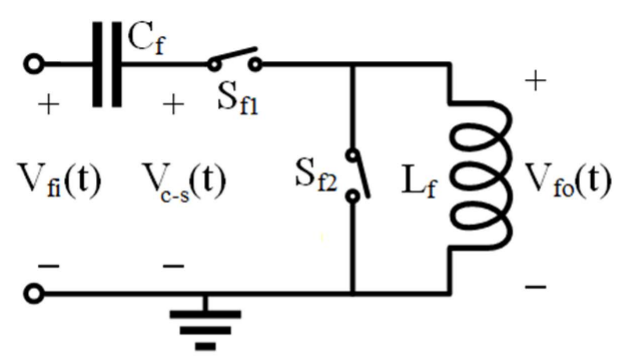

(a)

Figure 1. Cont. 


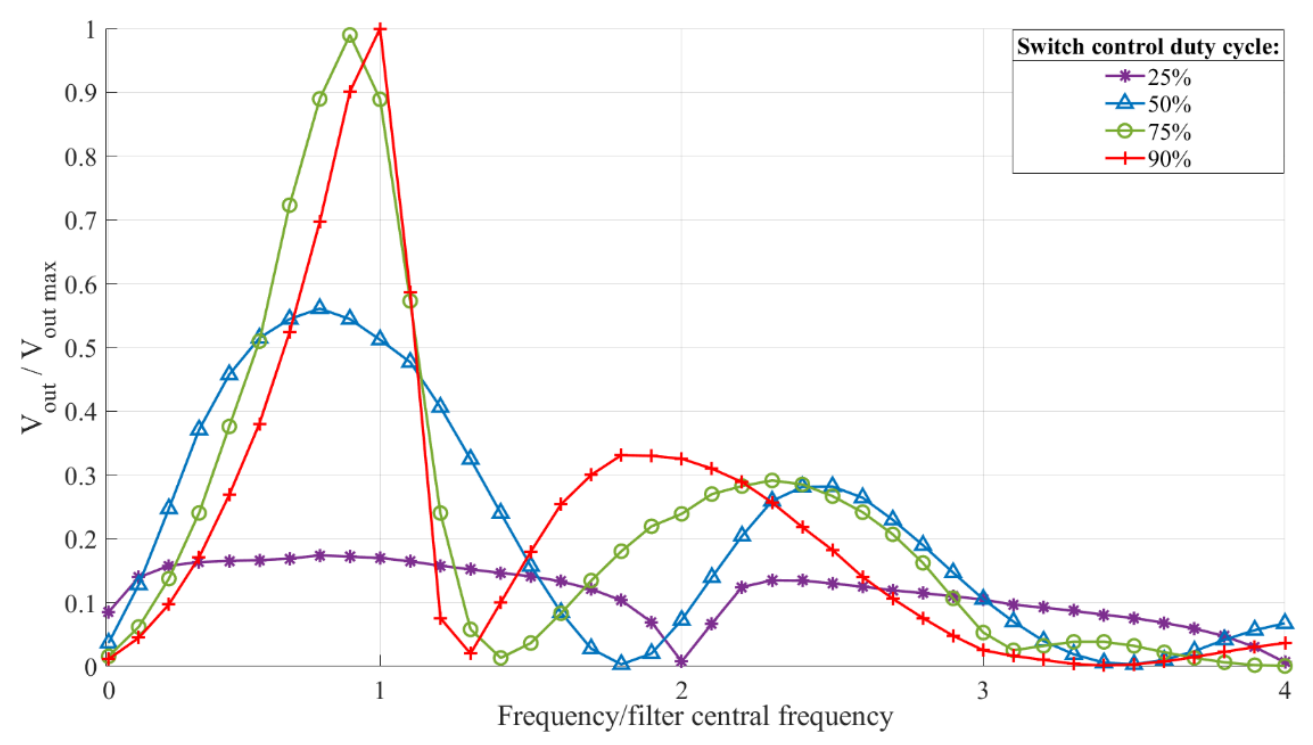

(b)

Figure 1. (a) Switched inductor filter and (b) its qualitative frequency characteristic with the duty cycle of $25 \%$ (purple), $50 \%$ (blue), $75 \%$ (green), and $90 \%$ (red). Filter output voltage RMS is normalized with regards to maximal output voltage RMS (obtained with the $90 \%$ duty cycle at the input frequency equal to filter central frequency), input signal frequency normalized with regards to the filter's central frequency.

The passive LC filter has a resonant frequency, $f_{\text {res }}$ :

$$
f_{\text {res }}=\frac{1}{2 \pi \sqrt{L_{f} C_{f}}}
$$

where $L_{f}$ and $C_{f}$ are the values of inductance and capacitance, respectively. By switching the inductor on and off, its effective value, $L_{f e f f}$, seen at the circuit input, is changed, which changes the filter's frequency characteristics. The two switches, $S_{f 1}$ and $S_{f 2}$, (Figure 1a) are driven by two antiparallel square signals, with switch $S_{f 2}$ closing when $S_{f 1}$ opens to provide a discharge current path for the inductor. The switching function $F_{1}(t)$ of the switch $S_{1}$ is given as [20]:

$$
F_{1}(t)=A_{0}+2 \sum_{n=1}^{\infty} \frac{\sin \left(n \omega \frac{d}{2}\right)}{n \pi} \cos (n \omega t-n \theta)
$$

where $t$ denotes time, $d$ and $\theta$ are the pulse duration and the phase delay of the switch control function, respectively, $\omega$ is the angular frequency of the switch control signal, $n$ is a positive integer, and $A_{0}$ is the average value of the switching function on its single period $T$. The average value of the switching function is determined by its duty cycle, i.e., the ratio of the duration of the function's high state and its period, $A_{0}=d / T$. The switching function takes on the value of 1 when the switch is closed and 0 when it is open.

The authors of $[19,20]$ do not analyze the influence of the switch control function frequency on the filter functionality. They only state that it should be higher than input signal frequency $f_{\text {in }}$.

The filter output voltage, $V_{f_{0}}(t)$, is determined by the voltage of the node between the filter capacitor $C_{f}$ and switch $S_{f 1}, V_{c-s}(t)$, and the switching function $F_{1}(t)$ :

$$
V_{f o}(t)=F_{1}(t) \cdot V_{c-s}(t)
$$


From Equations (2) and (3) and a few steps presented in [20], it can be determined that the effective value of the filter inductance $L_{f e f f}$ is proportional to:

$$
L_{f e f f} \propto \frac{L_{f}}{A_{0}{ }^{2}}
$$

and therefore, dependent on the average value of the switching function, which is, as shown previously, determined by the switching function's duty cycle that can be used to tune the filter's frequency characteristic, as shown in Figure $1 b$.

\subsection{Switched Harvester on Inductor}

The switched harvester on inductor (one version shown in Figure 2a) is used to increase the efficiency in energy harvesting, by boosting the harvester's transducer voltage, $V_{t r}(t)$, prior to rectification (as shown in Figure 2b) [12,13,16].

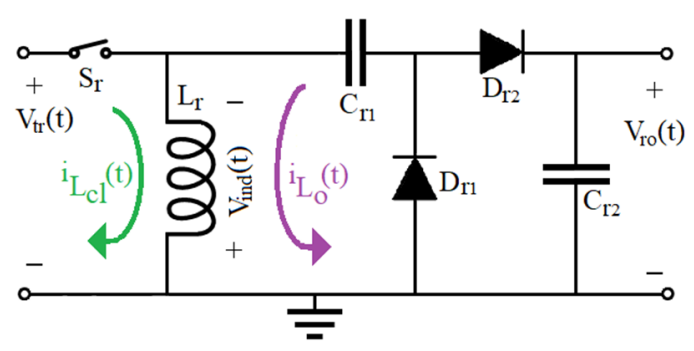

(a)

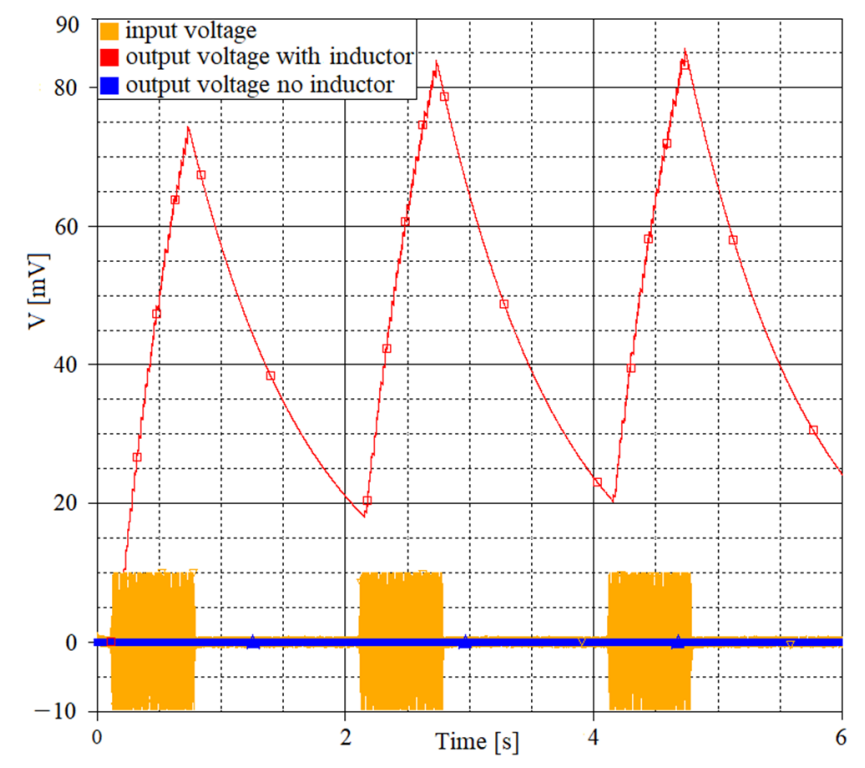

(b)

Figure 2. (a) Switched harvester on inductor with marked inductor current, $i_{L c l}(t)$ (green) and $i_{L o}(t)$ (purple) with the switch closed and opened, respectively. (b) Switched harvester on inductor output signal waveform (red) compared to a rectifier without the switched inductor (blue). Input signal (yellow): $500 \mathrm{~ms}$ of sinusoidal signal, $20 \mathrm{mV}$ peak-to-peak, $100 \mathrm{~Hz}$, followed by a $1.5 \mathrm{~s}$ pause. $C_{r 1}=C_{r 2}=1 \mu \mathrm{F}, L_{r}=100 \mathrm{mH}$, switch control frequency $f_{\text {switch }}=256 \mathrm{~Hz}$, duty cycle $50 \%$. 
While the switch $S_{r}$ is closed, the energy of the harvester's transducer signal is stored in the magnetic field of the inductor, $L_{r}$, changing the inductor's current by $\Delta i_{L}$ with:

$$
\Delta i_{L}=\frac{1}{L_{r}} \int_{t_{1}}^{t_{2}} V_{t r}(t) d t
$$

where $t_{1}$ and $t_{2}$ are, respectively, the beginning and ending moment of observing the storing of energy in the inductor's magnetic field, and $V_{t r}(t)$ is the harvester's transducer voltage.

At the moment $t_{0}$, when the switch opens, the energy stored in the inductor generates an induced voltage, $V_{\text {ind }}$ :

$$
V_{\text {ind }}=\left.L_{r} \frac{d i_{L}(t)}{d t}\right|_{t=t_{0}}
$$

We can approximate the time derivation of the inductor current at the moment $t_{0}$ as:

$$
\left.\frac{d i_{L}(t)}{d t}\right|_{t=t_{0}}=\frac{i_{L}\left(t_{O}\right)}{\Delta t}=\frac{\frac{1}{L_{r}} \int_{t_{C}}^{t_{O}} V_{t r}(t) d t}{\Delta t}
$$

where $i_{L}\left(t_{o}\right)$ is the inductor current at the instant of the switch opening, $t_{c}$ the time instant when the switch is closed, and $\Delta t$ is the time required for the inductor current to fall to zero.

If the voltages induced on the inductor are high enough to pass over the diodes, they will charge the output capacitor to the steady state voltage:

$$
V_{r O \_s s}=2 \cdot\left(\frac{\int_{t_{C}}^{t_{O}} V_{t r}(t) d t}{\Delta t}-V_{D}\right)
$$

where $V_{D}$ is the diode threshold voltage.

Neglecting energy losses, the maximal obtainable rectifier output voltage $V_{\text {ro_max }}$ depends on the inductance $L_{r}$, capacitance $C_{r 1,2}$, and the current through the inductor at the instant the switch opens, $i_{L}\left(t_{0}\right)(9)[21]$.

$$
V_{\text {ro_max }}=i_{L}\left(t_{O}\right) \cdot \sqrt{\frac{L_{r}}{C_{r 1,2}}}
$$

The output capacitor $C_{r 2}$ gradually discharges when no signal is coming from the harvester's transducer (as seen in Figure $2 b$ ) because of the leakage currents of the reversely polarized diodes, or the input impedance of the next interface stage.

\section{Proposed Sensor Interface Characteristics and Design Parameters}

Combining the two functionalities explored in the literature, in this work we devise a low-power, frequency selective, voltage boosting sensor interface (Figure 3a), capable of operating with signals under $5 \mathrm{mV}$ peak-to-peak and in the low acoustic frequency range, from $100 \mathrm{~Hz}$ to $1 \mathrm{kHz}$. For the interface to meet these demands, several of its characteristics should be considered. The first is the interface's sensitivity (Figure 3c), the ratio of output headroom voltage and input voltage, with the headroom voltage defined as the voltage difference between the interface output voltage with no input and the interface lowest steady-state output voltage with a given input, as shown in Figure 3b. The stopband sensitivity should also be considered, as the maximal expected stopband voltage defines the lowest passband voltage levels with which the interface can operate (spurious-free range, Figure 3c). This leads to the next characteristic, the frequency selectivity, i.e., the difference between its passband and stopband sensitivities (Figure 3c,d). The final characteristic is the power consumption. 


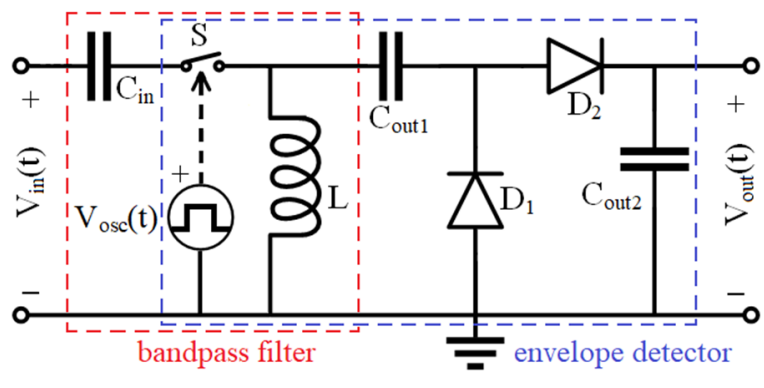

(a)

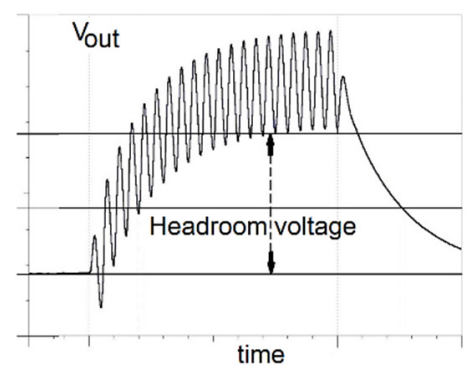

(b)

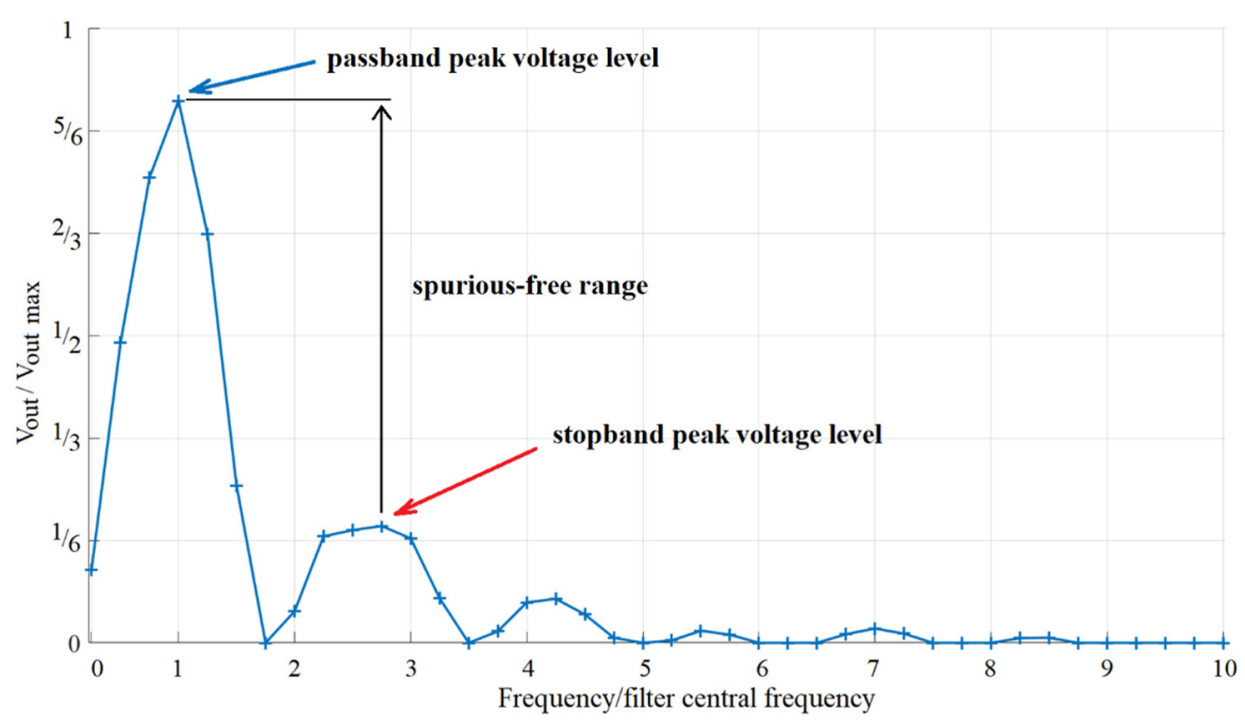

(c)

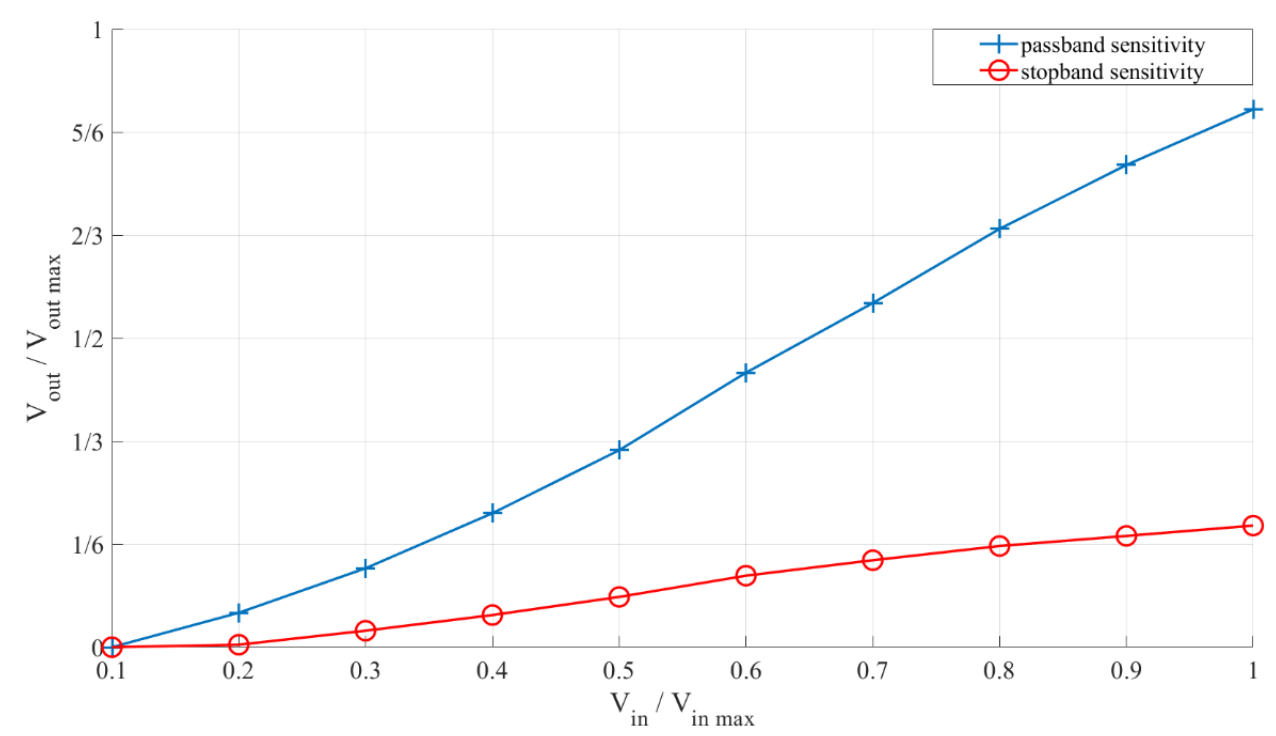

(d)

Figure 3. (a) Proposed sensor interface (with marked bandpass filter and envelope detector functional blocks), (b) output signal waveform (with marked headroom voltage), (c) normalized frequency characteristic and (d) normalized output headroom voltage with input voltage. 
From the presented principles of operation and the desired characteristics of the proposed interface, we determined its key design parameters that can be divided in two groups: switch control signal parameters and passive component values.

The switch control signal parameters of interest are: switch control signal frequency, duty cycle, and delay between the switch control and input signal (the switch is controlled by an independent voltage signal $V_{\text {osc }}(t)$, as shown in Figure $3 a$ ).

The passive components of interest are: input capacitor $C_{i n}$, inductor $L, Q$ factor of the input switched inductor filter, and output capacitors, $C_{\text {out } 1}$ and $C_{\text {out } 2 \text {, which we analyzed }}$ in detail in our previous work $[17,18]$. The diodes were also chosen based on previous work analyzing their influence on weak-signal rectifier performance [14,22].

\section{Proposed Sensor Interface Simulation Study}

\subsection{Simulation Model}

In order to both characterize the proposed sensor interface and narrow the parameter selection for the prototype realization, a SPICE model has been implemented and simulated in Texas Instruments' PSpice (Dallas, Texas, TX, USA) following the schematic shown in Figure 3a. The obtained simulation results were further processed and presented using MathWorks' MATLAB $^{\circledR}$ (Natick, Massachusetts, MA, USA).

The following parameters were varied to determine their influence on the output voltage characteristics and power consumption: switch control signal frequency and duty cycle, delay between the switch control signal and input signal, input capacitor, $C_{i n}$, inductor, $L$, and resistance, $R_{L}$, filter quality factor, $Q$, defined as:

$$
Q=\frac{1}{R_{L}} \cdot \sqrt{\frac{L}{C_{i n}}}
$$

The output capacitors, $C_{o u 1}$ and $C_{o u t 2}$ were both $1 \mu \mathrm{F}$, following previous research conclusions and the diodes chosen for the simulation model were the HSMS-282x (Agilent Technologies, Santa Clara, California, CA, USA), because of their low forward voltage, low reverse current, and high saturation current. For simulation analyses showing the frequency characteristics, the input, $V_{\text {in }}(t)$, was a sinusoidal signal with frequency varied from $50 \mathrm{~Hz}$ to $2000 \mathrm{~Hz}$, with a $50 \mathrm{~Hz}$ step and $20 \mathrm{mV}$ peak-to-peak, while the simulation analyses showing the sensitivity were done with an input sinusoidal signal of a fixed frequency in the range from $100 \mathrm{~Hz}$ to $600 \mathrm{~Hz}$ and voltage from $1 \mathrm{mV}$ to $20 \mathrm{mV}$ peak-topeak with a $1 \mathrm{mV}$ step.

\subsection{Simulation Results}

\subsubsection{Switch Control Signal Parameters-Duty Cycle and Frequency}

Figure $4 \mathrm{a}, \mathrm{b}$ show the interface frequency characteristic and the relation of output headroom voltage and input voltage with switch control signal duty cycle. The filter central frequency was $512 \mathrm{~Hz}\left(C_{i n}=1 \mu \mathrm{F}, L=100 \mathrm{mH}, R_{L}=66.6 \Omega(\mathrm{Q}=4.8335)\right)$. The switch control signal frequency was $1024 \mathrm{~Hz}$ and duty cycles were $25 \%, 33 \%, 50 \%, 66 \%$, and $75 \%$.

From Figure $4 \mathrm{a}$, b we see that increasing the switch control signal duty cycle leads to an increased sensitivity and a narrower frequency characteristic, both of which are desired traits. It also increases the central frequency of the interface passband towards the one of a fixed passive LC filter. These results adhere to the theoretical switched inductor filter performance presented in Section 2.1 and Figure 1b. We can also conclude that duty cycles under $50 \%$ should not be utilized, as they lead to low sensitivity and poorer frequency selectivity. 


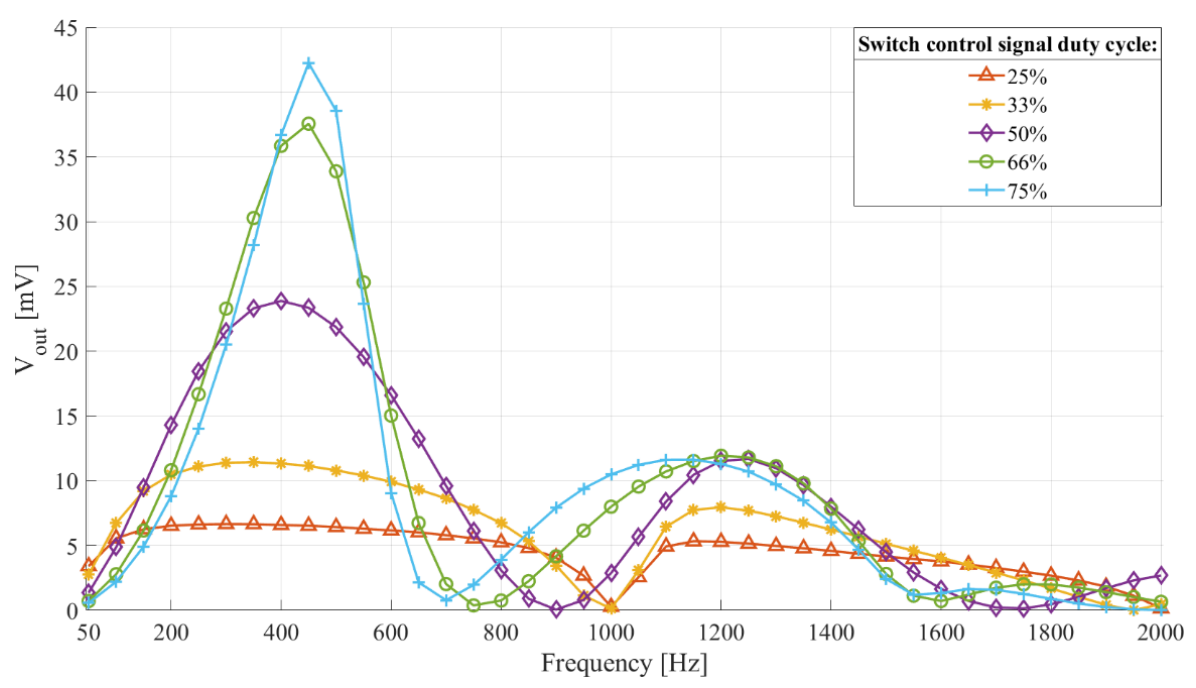

(a)

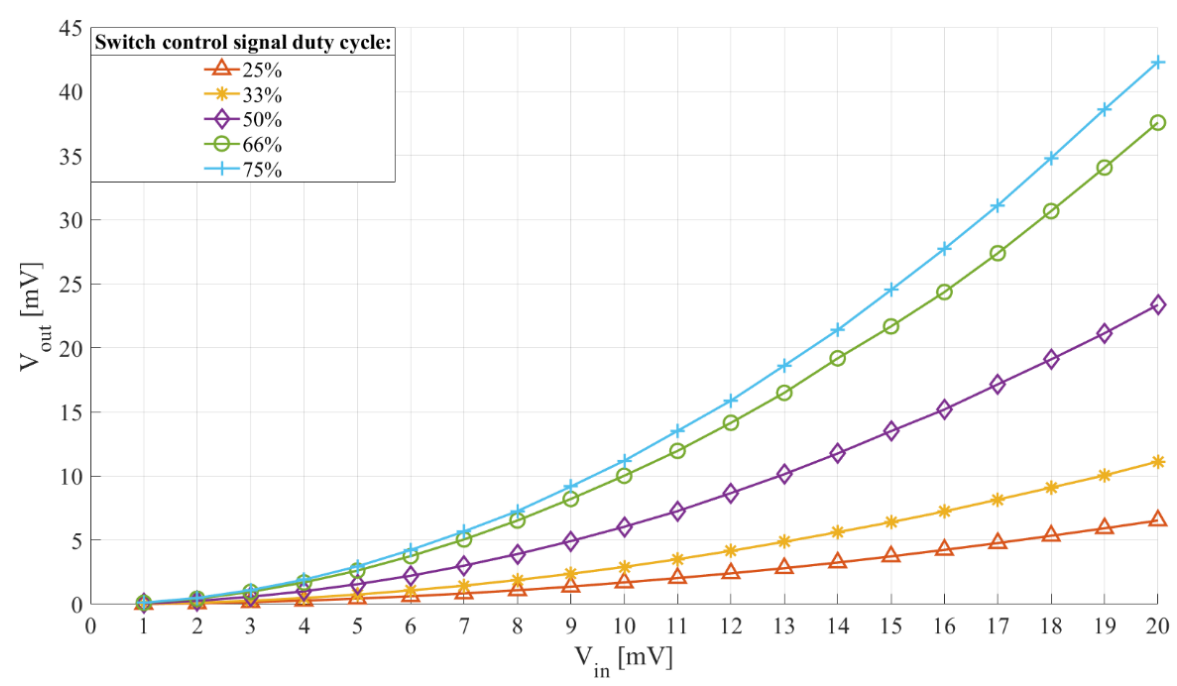

(b)

Figure 4. (a) Frequency characteristic and (b) output headroom voltage to input voltage relation of the sensor interface with switch control signal duty cycle. Filter central frequency $512 \mathrm{~Hz}(L=100 \mathrm{mH}$, $C_{\text {in }}=1 \mu \mathrm{F}, R_{L}=66.6 \Omega$ ). Switch control signal frequency $f_{\text {switch }}=1024 \mathrm{~Hz}$ and duty cycle from $25 \%$ to $75 \%$. (a) Input voltage $20 \mathrm{mV}$ peak-to-peak and frequency from $50 \mathrm{~Hz}$ to $2000 \mathrm{~Hz}$ with a $50 \mathrm{~Hz}$ step. (b) Input signal voltage from $1 \mathrm{mV}$ to $20 \mathrm{mV}$ with a $1 \mathrm{mV}$ step. Input signal frequency $450 \mathrm{~Hz}$.

However, increasing the duty cycle leads to longer periods of time in which the sensor drives the interface, leading to an increased sensor current. This is shown in Figure 5, which depicts the inductor current with switch control signal duty cycle. The simulation model was the same as for Figure $4 a, b$, and the switch control signal duty cycle was $25 \%$, $50 \%$, and $75 \%$. 


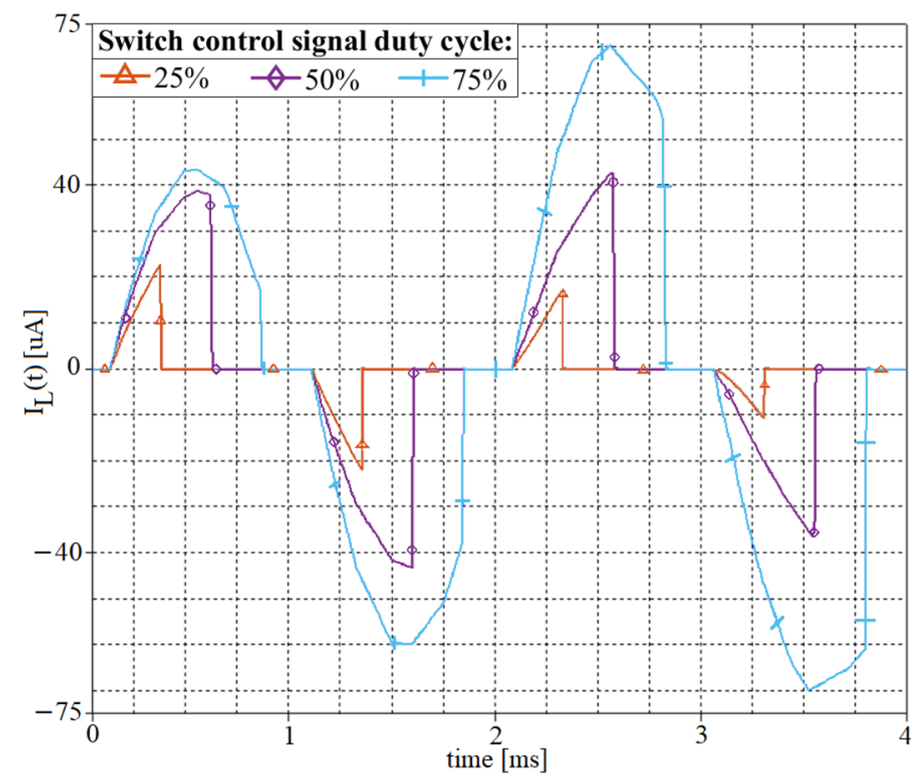

Figure 5. Inductor current of the sensor interface with switch control signal duty cycle. Filter central frequency $512 \mathrm{~Hz}\left(L=100 \mathrm{mH}, C_{i n}=1 \mu \mathrm{F}, R_{L}=66.6 \Omega\right)$. Switch control signal frequency $f_{\text {switch }}=1024 \mathrm{~Hz}$ and duty cycle $25 \%, 50 \%$, and $75 \%$. Input signal voltage $20 \mathrm{mV}$ peak-to-peak and frequency $450 \mathrm{~Hz}$.

As we can see from Figure 5, both peak and mean inductor currents are determined by the switch control signal duty cycle. The peak and mean currents were around $23 \mu \mathrm{A}$ peak and $2.88 \mu \mathrm{A}$ mean for $25 \%$ duty cycle, $42 \mu \mathrm{A}$ peak, and $10.5 \mu \mathrm{A}$ mean for $50 \%$ duty cycle, and $70 \mu \mathrm{A}$ peak and $26.25 \mu \mathrm{A}$ mean for $75 \%$ duty cycle.

Figure 6 shows the interface frequency characteristics with switch control signal frequency, $f_{\text {switch }}$. The filter central frequency was $512 \mathrm{~Hz}\left(C_{\text {in }}=1 \mu \mathrm{F}, L=100 \mathrm{mH}, R_{L}=66.6 \Omega\right.$ $(Q=4.8335))$. The switch control frequency was $256 \mathrm{~Hz}, 512 \mathrm{~Hz}, 1024 \mathrm{~Hz}$, and $2048 \mathrm{~Hz}$. The switch control signal duty cycle was $75 \%$.

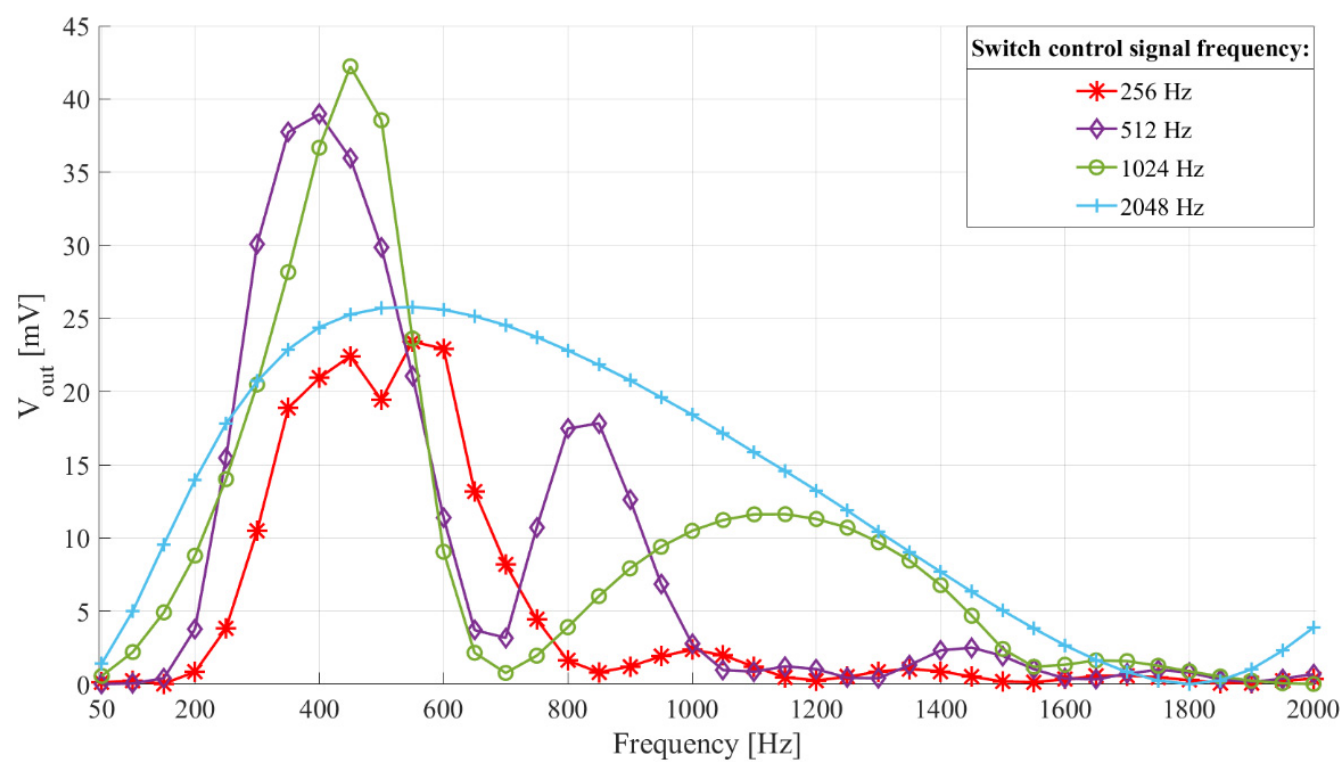

Figure 6. Frequency characteristics of the sensor interface with switch control frequency. Filter central frequency $512 \mathrm{~Hz}$ $\left(L=100 \mathrm{mH}, C_{i n}=1 \mu \mathrm{F}, R_{L}=66.6 \Omega\right)$. Input voltage $20 \mathrm{mV}$ peak-to-peak and frequency from $50 \mathrm{~Hz}$ to $2000 \mathrm{~Hz}$ with a $50 \mathrm{~Hz}$ step. Switch control signal frequency, $f_{\text {switch }}, 256 \mathrm{~Hz}, 512 \mathrm{~Hz}, 1024 \mathrm{~Hz}$, and $2048 \mathrm{~Hz}$ and duty cycle 75\%. 
Looking at Figure 6 we see that there is a switch control signal frequency that, with a given filter central frequency and $Q$ factor, leads to the most frequency selective interface, with the highest sensitivity (in this case it is $1024 \mathrm{~Hz}$, i.e., double the filter central frequency).

The dependency of the frequency characteristic and sensitivity on the switch control frequency can be explained by energy transfer from the input LC circuit to the output capacitors.

The maximal energy transfer occurs if the switch opens twice per inductor current period, precisely at maximal positive and negative inductor current values. The switch control signal frequency should be set slightly above double the frequency of the input signal of interest, to avoid the influence of time delay between the input and switch control signal on the output voltage (explained in the following text).

More than two switch openings per inductor current period cause more generations of induced voltage, but of lower value, which reduces the overall energy transfer efficiency, because of the exponential dependency of the diode current on the voltage on it, i.e., the induced voltage. Having more than two openings per input signal period also leads to a broader frequency characteristic (output voltage less dependent on the switch opening instant).

Finally, when considering the switch control signal parameters, it should be mentioned that the proposed sensor interface output voltage can also be influenced by the time delay between the input signal onset and the switch control signal. This effect explains the small discontinuities, like the one visible in Figure 6 at $500 \mathrm{~Hz}$, on the red curve. However, this delay can substantially influence the interface output voltage only if the input signal frequency matches the switch control signal frequency or one of its specific rational multipliers $(1 / 4,1 / 2,2,3 \ldots)$. For all other input signals, this time delay can change the output voltage by no more than $10 \%$. Therefore, this effect will not substantially impact the device's application and performance with transducer inputs (which consist of frequencies of interest, other frequencies, noise, and interference).

\subsubsection{Passive Component Selection-Capacitor and Inductor}

From Equation (1) it is clear that the same central frequency can be obtained with different values of inductance, $L$, and capacitance, $C$. This is shown in Figure $7 \mathrm{a}, \mathrm{b}$, which present the frequency characteristics and the relation of the output headroom voltage and input voltage of interfaces with different inductance and capacitance. The filter central frequency was $512 \mathrm{~Hz}$, the switch control frequency was $1080 \mathrm{~Hz}$, and the duty cycle was $75 \%$. $L$ were $100 \mathrm{mH}, 350 \mathrm{mH}$, and $590 \mathrm{mH}$, and $C_{\text {in }}$, were $1 \mu \mathrm{F}, 276 \mathrm{nF}$, and $164 \mathrm{nF}$, respectively. The $Q$ factor was kept constant $(Q=267.3)$ by setting the resistance, $R_{L}$, to $1.2 \Omega, 4.2 \Omega$, and $7.1 \Omega$, respectively.

From Figure $7 \mathrm{a}, \mathrm{b}$ we see that interfaces with filters set to the same central frequency, have lower sensitivity the higher their inductance is. Furthermore, if we compare the results from Figure $4 \mathrm{~b}$ with the results from Figure $7 \mathrm{~b}$ we can see that an interface with a significantly lower $Q$ factor (Figure $4 \mathrm{~b}, Q=4.8335$ ) still has higher sensitivity than the two interfaces with higher inductances and higher $Q$ factor (Figure $7 \mathrm{~b}$, $Q=267.3$ ). 


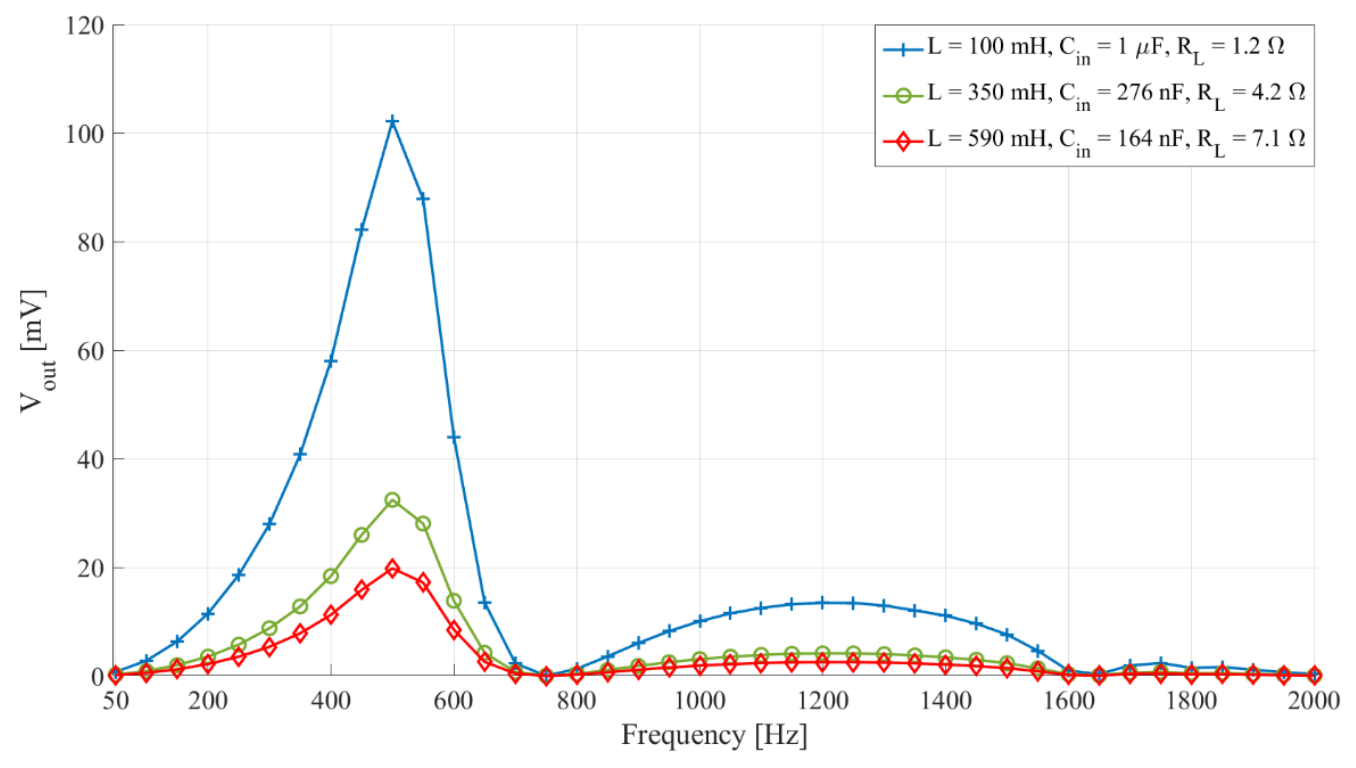

(a)

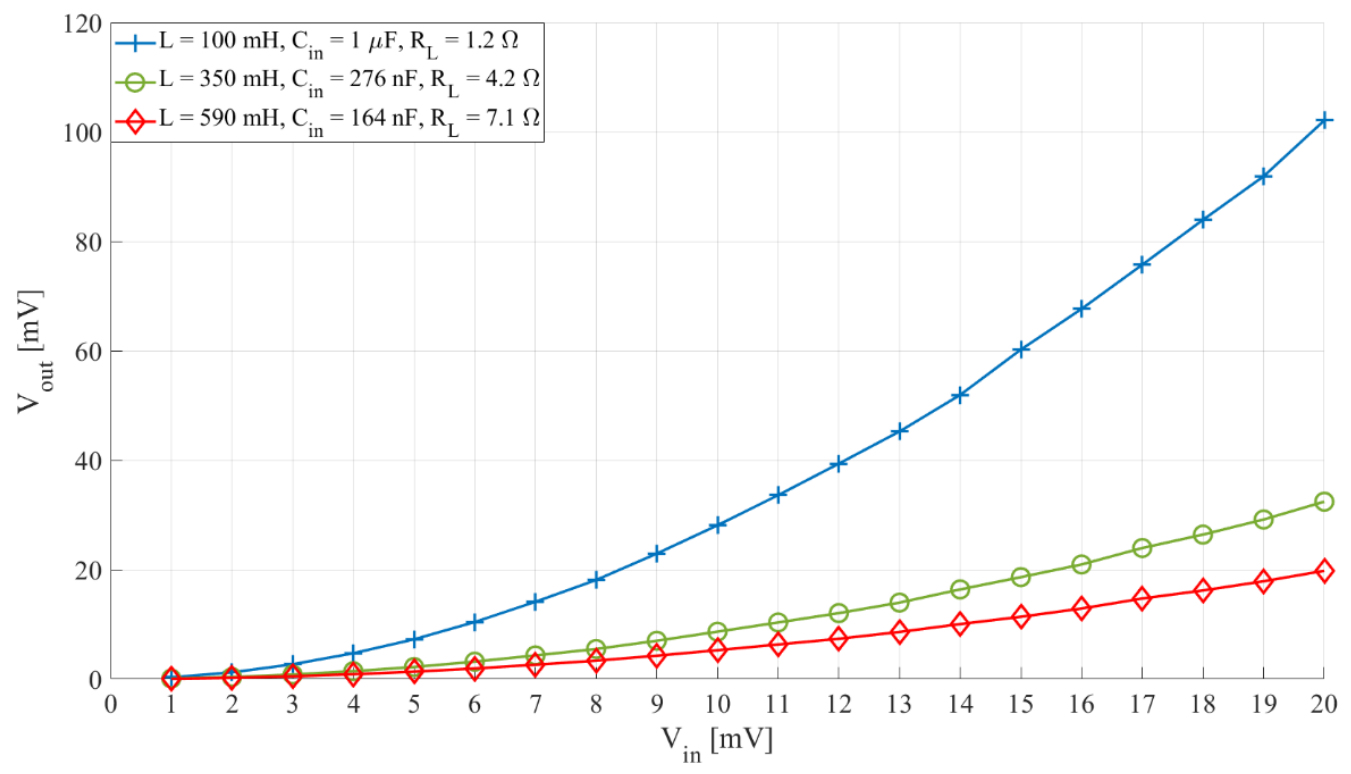

(b)

Figure 7. (a) Sensor interface frequency characteristic and (b) the relation of output headroom voltage and input voltage with $L$. The switch control frequency, $f_{\text {switch }}, 1080 \mathrm{~Hz}$ and duty cycle $75 \%, Q=267.3$. (a) Input signal voltage $20 \mathrm{mV}$ peak-to-peak, frequency from $50 \mathrm{~Hz}$ to $2000 \mathrm{~Hz}$ with a $50 \mathrm{~Hz}$ step. (b) Input signal frequency $500 \mathrm{~Hz}$ and voltage from $1 \mathrm{mV}$ to $20 \mathrm{mV}$ peak-to-peak with a $1 \mathrm{mV}$ step.

\section{Proposed Sensor Interface Experimental Characterization}

The goal of these measurements was to provide experimental verification of the simulation results and characterize the proposed sensor interface prototype in terms of frequency selectivity, sensitivity, and power consumption.

\subsection{Measurement Setup}

Figure 8a shows a photograph of the measurement setup. The measurement setup consisted of a Keysight 33500B waveform generator (Keysight Technologies, Santa Rosa, California, CA, USA) for generating the input and switch control signal, the prototype 
sensor interface (shown in Figure 8b), and an NI USB-6211 (National Instruments, Austin, Texas, TX, USA) data acquisition card connected to a PC for recording the output voltage. The power consumption of the interface was measured using a Fluke 45 multimeter (Fluke Corporation, Everett, Washington, WA, USA). The interface was powered by a DP832 power source from RIGOL (RIGOL Technologies, Beijing, China).

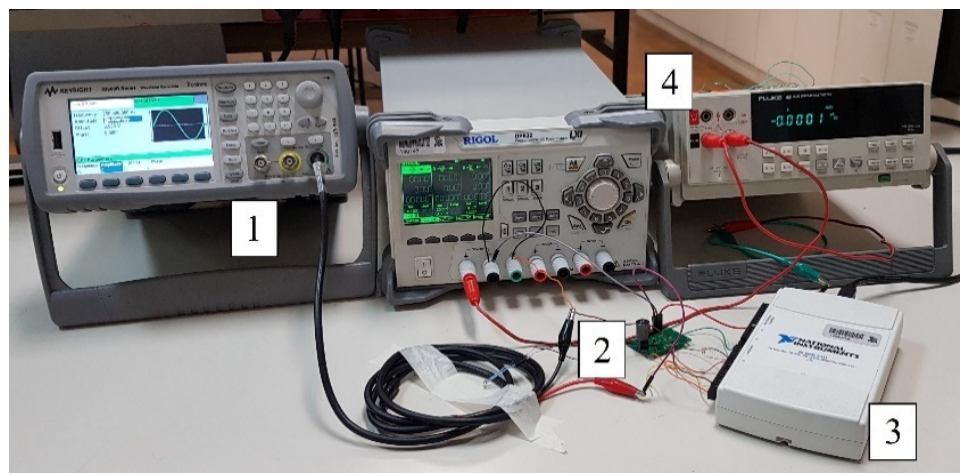

(a)

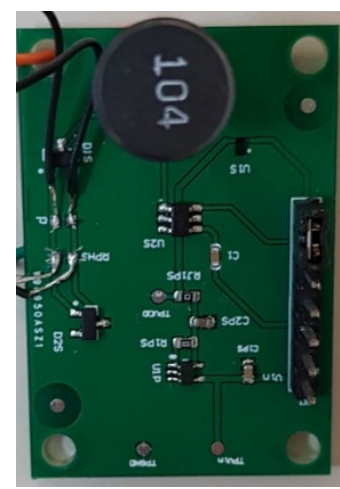

(b)

Figure 8. (a) A photograph of the measurement setup. (1) Keysight 33500B waveform generator, (2) sensor interface prototype, (3) NI USB-6211 data acquisition card. (4) Power supply (RIGOL DP832) and a multimeter for supply current measurement (Fluke 45). (b) Proposed frequency-selective voltage-boosting sensor interface prototype.

The prototype of the proposed frequency-selective voltage-boosting sensor interface was designed according to the schematic in Figure 3a, with components shown in Table 1.

Table 1. Prototype components.

\begin{tabular}{|c|c|c|c|c|}
\hline \multicolumn{5}{|c|}{ Integrated Components } \\
\hline Component & Manufacturer & Supply Voltage & $\begin{array}{l}\text { Supply Current } \\
\text { (Typical) }\end{array}$ & $\begin{array}{l}\text { Transition Times } \\
\text { (Typical) }\end{array}$ \\
\hline switch TMUX1101 & Texas Instruments & $1.8 \mathrm{~V}$ & $3 \mathrm{nA}$ & $12 \mathrm{~ns}$ \\
\hline oscillator SiT1569 & SiTime & $1.8 \mathrm{~V}$ & $1.7 \mu \mathrm{A}-3.3 \mu \mathrm{A}$ & $200 \mathrm{~ns}$ \\
\hline \multicolumn{5}{|c|}{ Discrete Semiconductor Components } \\
\hline Component & Manufacturer & Reverse Current (at 1V) & Saturation Current & $\begin{array}{c}\text { Forward Voltage } \\
\text { (Maximal) }\end{array}$ \\
\hline diodes HSMS-282x & Agilent & $100 \mathrm{nA}$ & $22 \mathrm{nA}$ & $0.34 \mathrm{~V}$ \\
\hline \multicolumn{5}{|c|}{ Discreet Passive Components } \\
\hline \multicolumn{2}{|c|}{ Component } & \multicolumn{2}{|c|}{ Value } & Type \\
\hline \multicolumn{2}{|c|}{ Output capacitors } & \multicolumn{2}{|c|}{$C_{\text {out }_{1}}=C_{\text {out } 2}=1 \mu \mathrm{F}$} & Multilayer ceramic \\
\hline \multicolumn{2}{|c|}{ Input capacitors } & \multicolumn{2}{|c|}{$C_{i n_{1}}=100 \mathrm{nF}, C_{i n 2}=1 \mu \mathrm{F}, C_{i n 3}=2.2 \mu \mathrm{F}$} & Multilayer ceramic \\
\hline \multirow{2}{*}{\multicolumn{2}{|c|}{ Inductors }} & \multicolumn{2}{|c|}{$L_{1}=100 \mathrm{mH}, R_{L 1}=66.6 \Omega$} & Air-core \\
\hline & & \multicolumn{2}{|c|}{$L_{2}=590 \mathrm{mH}, R_{L 2}=7.1 \Omega$} & Ferrite-core \\
\hline
\end{tabular}

\subsection{Measurement Procedure and Results}

The measurement results were recorded by a National Instruments NI USB-6211 data acquisition card. The data acquisition control, data processing, and presentation were implemented using MathWorks' MATLAB ${ }^{\circledR}$ (Natick, Massachusetts, MA, USA). 


\subsubsection{Frequency Selectivity}

The goal was to characterize the sensor interface frequency selectivity with different input capacitors, $C_{i n}$, inductors, $L$, and switch control signal frequencies.

The filter central frequencies were: $139 \mathrm{~Hz}\left(C_{i n 3}, L_{2}\right), 211 \mathrm{~Hz}\left(C_{i n 2}, L_{2}\right), 512 \mathrm{~Hz}\left(C_{i n 2}\right.$, $\left.L_{1}\right)$, and $655 \mathrm{~Hz}\left(C_{i n 1}, L_{2}\right)$. The switch control signal duty cycle was $50 \%$ and the frequency was $256 \mathrm{~Hz}, 278 \mathrm{~Hz}, 422 \mathrm{~Hz}, 512 \mathrm{~Hz}, 1024 \mathrm{~Hz}$, and $1310 \mathrm{~Hz}$. The input signal voltage was $20 \mathrm{mV}$ peak-to-peak and the frequency was ranging from $50 \mathrm{~Hz}$ to $2000 \mathrm{~Hz}$, with a $50 \mathrm{~Hz}$ step.

Figure 9 shows the frequency characteristics of the interface with four filter central frequencies and Figure 10 shows the frequency characteristics of an interface with a filter central frequency of $512 \mathrm{~Hz}$ and three different switch control signal frequencies. In addition to the measurement results, both figures show the simulation results for the same setups.

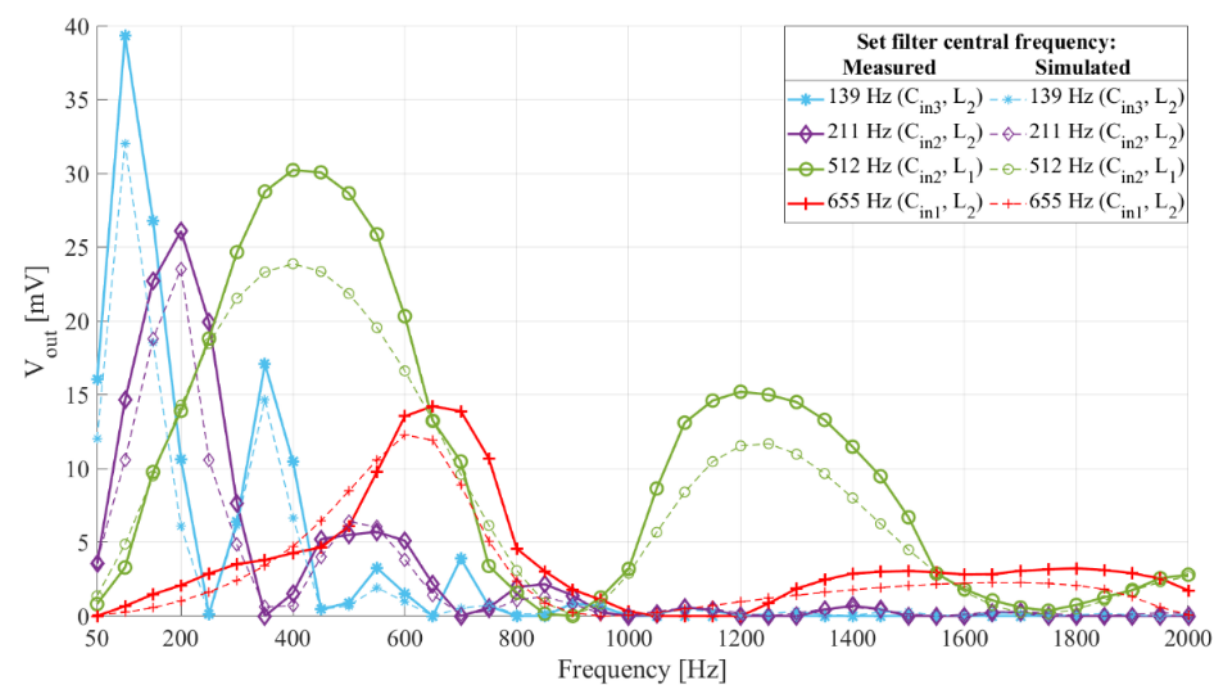

Figure 9. Frequency characteristic of the sensor interface prototype with different $C_{i n}, L$ and $R_{L}$. The switch control duty cycle 50\%. The switch control frequencies were $278 \mathrm{~Hz}$ (blue), $422 \mathrm{~Hz}$ (purple), $1024 \mathrm{~Hz}$ (green), and $1310 \mathrm{~Hz}$ (red). The dashed lines show simulation results, paired with the experimental results by color and same markers.

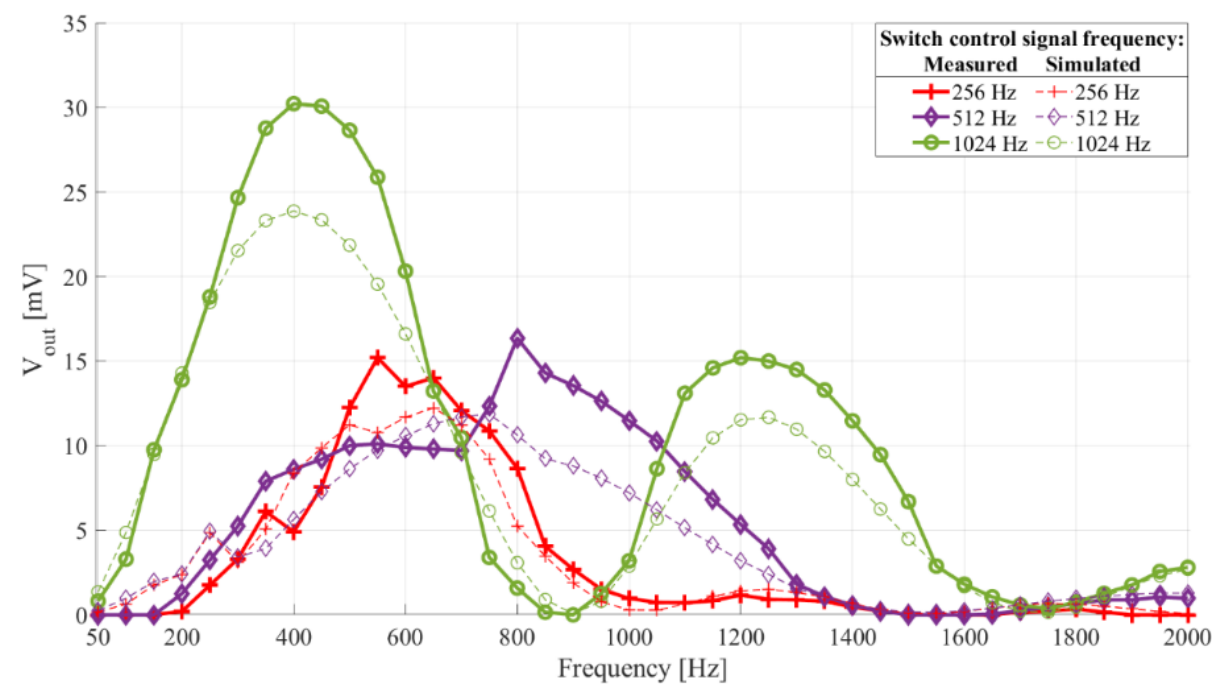

Figure 10. Frequency characteristic of the sensor interface prototype with the filter central frequency $512 \mathrm{~Hz}\left(C_{i n 2}, L_{1}\right)$. Switch control duty cycle $50 \%$, frequency $256 \mathrm{~Hz}, 512 \mathrm{~Hz}$, and $1024 \mathrm{~Hz}$. The dashed lines show simulation results, paired with the experimental results by color and same markers. 
Comparing the experimental and simulation results shown in Figures 9 and 10, we see the frequency characteristics of the prototype interface match those of the simulated interfaces.

In $[6,23]$ the authors presented the idea of reducing power consumption of wakeup interfaces and increasing their flexibility with reconfigurability, while in [10] digital setting of the filter central frequency was presented as an interesting feature for a wake-up interface. From the results in Figure 9, the filter central frequency of this interface can be digitally set by simultaneously selecting the input capacitor and switch control frequency. The settling time of the reconfigurable switched inductor circuit can be shorter than of that of a circuit utilizing an operational amplifier-based active bandpass filters.

\subsubsection{Sensitivity}

The goal was to determine the sensor interface sensitivity with different filter central frequencies (different input capacitors, $C_{i n}$, and inductors, $L$ ) and switch control signal frequencies.

The prototype setup was identical to the one described for frequency selectivity measurement. The input signal frequency was $100 \mathrm{~Hz}, 200 \mathrm{~Hz}, 450 \mathrm{~Hz}$, and $650 \mathrm{~Hz}$ and, the voltage was ranging from $2 \mathrm{mV}$ peak-to-peak to $20 \mathrm{mV}$ peak-to-peak with a $2 \mathrm{mV}$ step.

Figure 11 shows the measured and simulated output headroom voltage with input voltage of the interface whose frequency characteristics are shown in Figure 9, while Figure 12 shows the measured passband and stopband output-to-input voltage relation of two setups of the interface, with an input signal frequency of $200 \mathrm{~Hz}$ and $500 \mathrm{~Hz}$ for the $211 \mathrm{~Hz}$ filter central frequency setup, and $450 \mathrm{~Hz}$ and $1200 \mathrm{~Hz}$ for the $512 \mathrm{~Hz}$ filter central frequency setup.

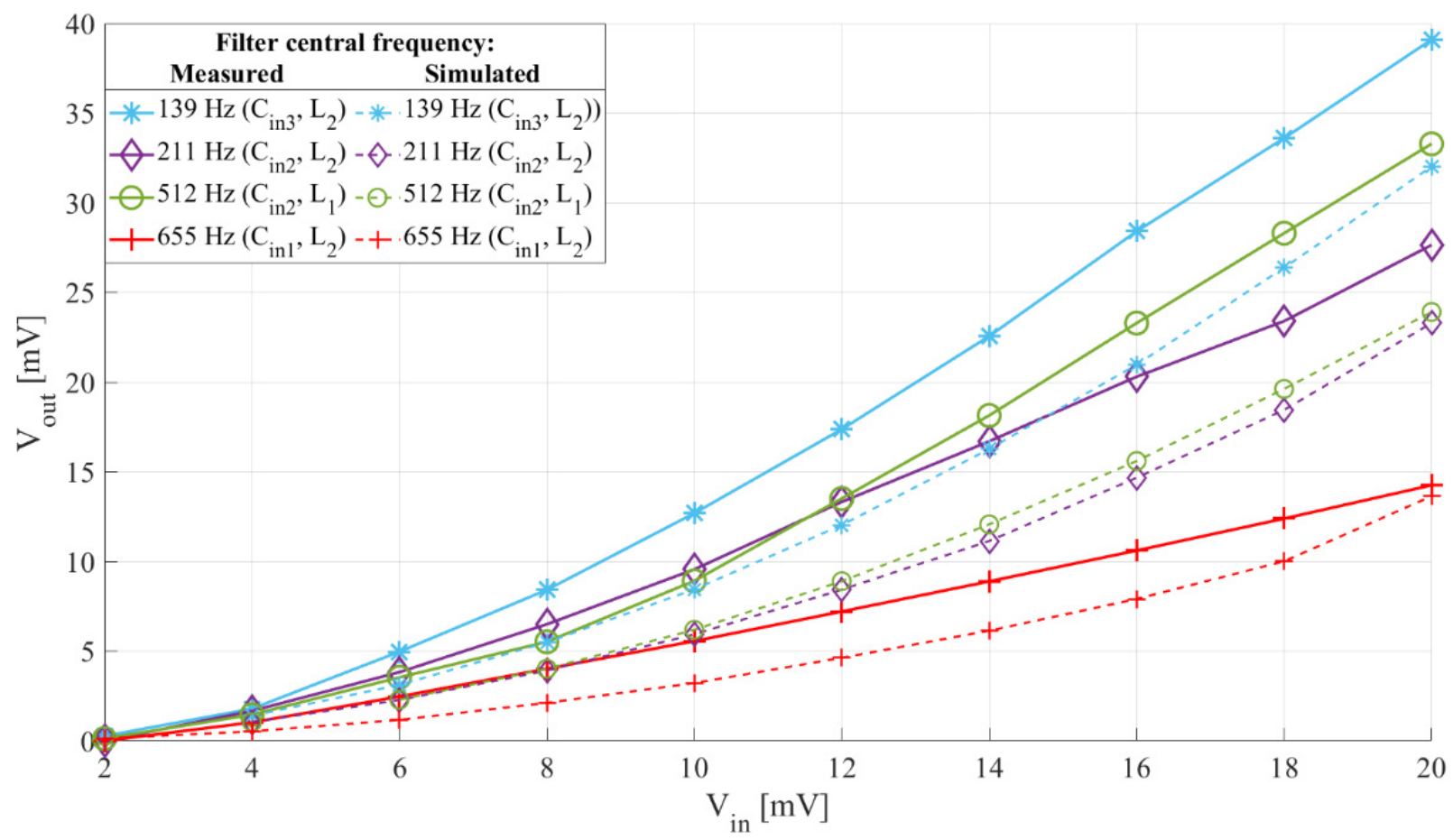

Figure 11. Sensor interface output headroom voltage to input voltage relation with different $C_{i n}$, and $L$. Switch control frequency $278 \mathrm{~Hz}$ (blue), $422 \mathrm{~Hz}$ (purple), $1024 \mathrm{~Hz}$ (green), and $1310 \mathrm{~Hz}$ (red), and duty cycle 50\%. Input signal frequency $100 \mathrm{~Hz}$ (blue), $200 \mathrm{~Hz}$ (purple), $450 \mathrm{~Hz}$ (green) and $650 \mathrm{~Hz}$ (red), and voltage from $2 \mathrm{mV}$ to $20 \mathrm{mV}$ peak-to-peak with a $2 \mathrm{mV}$ step. The dashed lines show simulation results, paired with the experimental results by color and same markers. 


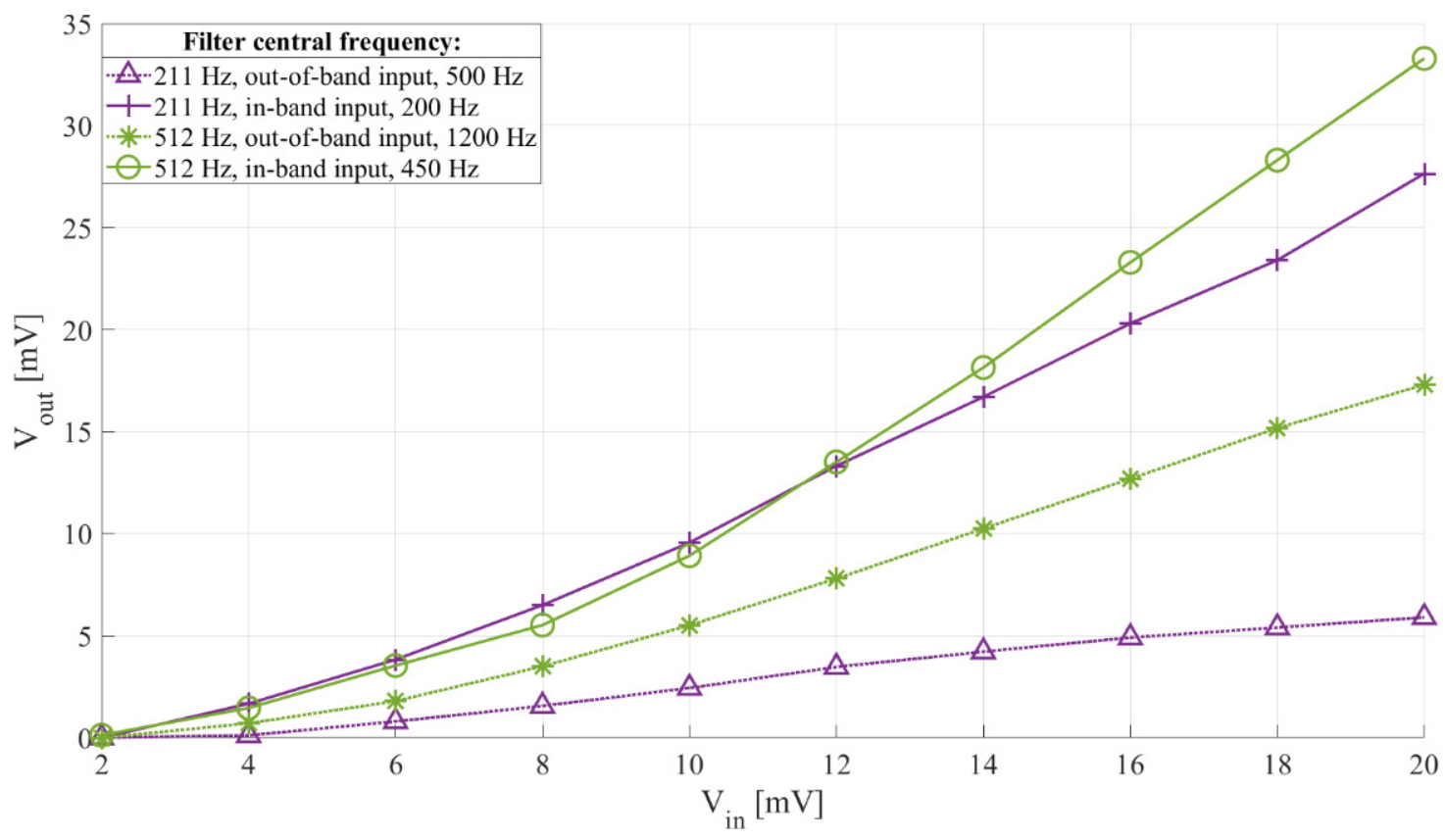

Figure 12. Sensor interface passband and stopband output and input voltage relation with $C_{i n}$, and $L$. Filter central frequency $211 \mathrm{~Hz}\left(C_{i n 2}, L_{2}\right)$ and $512 \mathrm{~Hz}\left(C_{i n 2}, L_{1}\right)$. The switch control frequency $422 \mathrm{~Hz}$ and $1024 \mathrm{~Hz}$, respectively, and the duty cycle $50 \%$. Input signal frequency $200 \mathrm{~Hz}$ and $500 \mathrm{~Hz}$ for the $211 \mathrm{~Hz}$ interface, and $450 \mathrm{~Hz}$ and $1200 \mathrm{~Hz}$ for the $512 \mathrm{~Hz}$ setting, and voltage from $2 \mathrm{mV}$ to $20 \mathrm{mV}$ peak-to-peak with a $2 \mathrm{mV}$ step.

From Figure 11 we can see that the sensitivity of the proposed sensor interface reaches up to approximately $2 \mathrm{mV} / \mathrm{mV}$ and it can be adjusted by choosing the input capacitor, $C_{i n}$, inductor, $L$, and switch control signal frequency. Comparing the experimental and simulation results shown in Figure 11, we see that the sensitivities and their trends of the developed prototype match those of the simulated interfaces.

From Figure 12 we can see that when the interface filter is set to $512 \mathrm{~Hz}$, the interface has a higher passband sensitivity (around $1.66 \mathrm{mV} / \mathrm{mV}$ ) than when it is set to $211 \mathrm{~Hz}$ (around $1.38 \mathrm{mV} / \mathrm{mV}$ ), but also, due to the lower $Q$ factor, it leads to a higher stopband sensitivity $(0.87 \mathrm{mV} / \mathrm{mV}$ compared to around $0.3 \mathrm{mV} / \mathrm{mV})$, making the $211 \mathrm{~Hz}$ interface setting more than twice more frequency selective than the $512 \mathrm{~Hz}$ one.

\subsubsection{Power Consumption}

The goal was to determine the power consumption of the proposed sensor interface prototype with selected components: the $1024 \mathrm{~Hz} \mathrm{SiT1569}$ oscillator, the input capacitor $C_{\text {in } 2}$ and inductor $L_{1}$. The power consumption was determined by multiplying the interface supply voltage of $1.8 \mathrm{~V}$ with its supply current, measured by a Fluke 45 multimeter.

The measured interface current consumption, consisting of the oscillator and switch current consumptions, was $1.84 \mu \mathrm{A}$, with a $1.8 \mathrm{~V}$ power supply, resulting in a power consumption of $3.31 \mu \mathrm{W}$.

The overall power consumption was predominantly defined by the oscillator, further emphasizing the crucial role of the switch control signal generator selection in achieving low power consumption.

\section{Design Recommendations}

Following the numerical and experimental analyses of the interface's functionality and design parameters, this section presents a set of recommendations for interface synthesis.

The interface synthesis is performed in a series of steps:

1. Choosing the output capacitors $C_{\text {out } 1}$ and $C_{\text {out } 2}$ to ensure the desired output signal waveform and its key parameters (more details in $[17,18]$ ). 
2. Determining the wanted frequency characteristic of the interface, by choosing its resonant frequency, $f_{\text {res }}$, (and angular frequency $\omega_{\text {res }}=2 \pi f_{\text {res }}$ ) and $Q$ factor. This choice is made considering the frequency characteristic of the input signal of interest. 3. Setting the desired sensitivity at the resonant frequency.

When considering Equation (9) for determining the maximal obtainable output voltage of the proposed interface, the inductor current can be expressed using the input voltage and input circuit impedance, $Z_{\text {in }}$ :

$$
V_{\text {out }}=\frac{V_{\text {in }}}{\left|Z_{\text {in }}\right|} \sqrt{\frac{L_{r}}{C_{\text {out } 1,2}}}
$$

with $Z_{\text {in }}$ given as:

$$
\left|Z_{\text {in }}\right|=\sqrt{\left(\omega_{\text {in }} \cdot L-\frac{1}{\omega_{i n} \cdot C_{i n}}\right)^{2}-R_{L}{ }^{2}}
$$

where $\omega_{\text {in }}$ is the input signal angular frequency.

From this, we can get an expression for the maximal sensitivity (at the resonant frequency):

$$
\frac{V_{\text {out }}}{V_{\text {in }}}=\frac{1}{\sqrt{L}} \cdot \frac{Q}{\omega_{\text {res }} \cdot \sqrt{C_{\text {out } 1,2}}}
$$

where $\omega_{\text {res }}$ is the input circuit resonant angular frequency, and $Q$ the quality factor, given in Equation (10).

From Equation (13), it is clear that, with a chosen output capacitance, input circuit resonant frequency and $Q$ factor, the interface sensitivity at the resonant frequency is set by choosing the appropriate inductance value.

4. Setting the switch control signal duty cycle to $50 \%$, as this provides a suitable sensitivity, frequency selectivity and power consumption. Small increases of the duty cycle can be considered for slight central frequency tuning, despite of increasing the design complexity, but not over $60 \%$, due to increased power consumption.

5. Setting the switch control signal frequency, $f_{\text {switch }}$, to around $2 \%$ to $5 \%$ higher than double of the frequency of the input signal of interest.

$$
f_{\text {switch }}=(1.02 \sim 1.05) \cdot 2 f_{\text {in }}
$$

To conclude this set of design guidelines, an exemplary evaluation of the maximal obtainable sensitivity is shown for one interface setup utilized in the experiments and simulations. With a filter central frequency of $f_{\text {res }}=512 \mathrm{~Hz}$, a $Q$ factor of around 4.8 , an inductor of $L=100 \mathrm{mH}$, and output capacitors of $C_{\text {out } 1,2}=1 \mu \mathrm{F}$, we get a maximal obtainable interface sensitivity of around $4.7 \mathrm{mV} / \mathrm{mV}$.

\section{Functional Test and Comparison}

\subsection{Measurement Setup}

The measurement setup for comparison of the proposed interface and one consisting of an active bandpass filter and a passive voltage doubler [9] was the same as for the experimental characterization of the proposed sensor interface (Figure 8a).

The proposed sensor interface's (Figure 3a) filter central frequency was $512 \mathrm{~Hz}$ with a $400 \mathrm{~Hz}$ bandwidth $\left(C_{\text {in }}=1 \mu \mathrm{F}, L=100 \mathrm{mH}, R_{L}=66.6 \Omega\right)$. Its switch control signal duty cycle was $50 \%$ and the frequency was $1024 \mathrm{~Hz}$. The output capacitors, $C_{\text {out } 1}$ and $C_{\text {out } 2 \text {, were }}$ $1 \mu \mathrm{F}$, and the HSMS-282x diodes, the TMUX1101 switch, and the SiT1569 $1024 \mathrm{~Hz}$ oscillator were used.

It was compared to a sensor interface consisting of an active general impedance converter (GIC) bandpass filter and a passive two-diode voltage doubler, as shown in Figure $13[9,18]$. The filter central frequency was $500 \mathrm{~Hz}$, with a passband bandwidth of 
around $300 \mathrm{~Hz}$. The rectifier capacitors $C_{r 1}$ and $C_{r 2}$ were $22 \mathrm{nF}$, to allow the capacitor to fully charge and achieve maximal headroom voltage during each event of interest $[17,18]$.

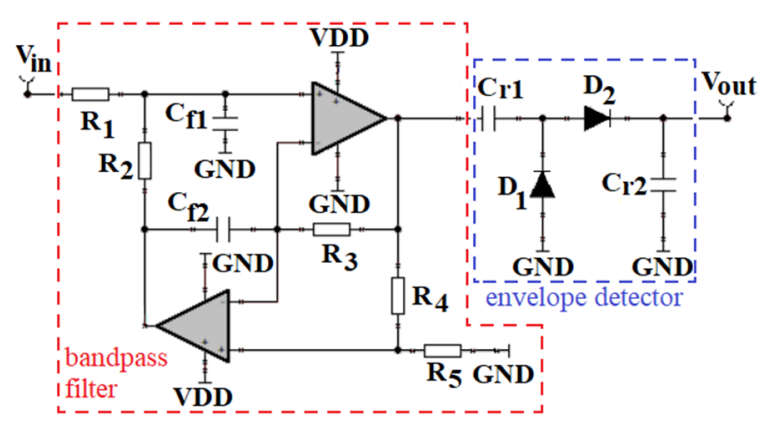

Figure 13. Schematic of the sensor interface consisting of an active GIC bandpass filter and a passive two-diode voltage doubler $[9,18]$.

\subsection{Measurement Procedure}

The two compared interfaces consist of the same two functional blocks (bandpass filter and envelope detector) and perform the same function of frequency signal decomposition and envelope extraction. To establish if the previously developed interface can be replaced by the one proposed in this work, a comparison of their output headroom voltages (Figure 3b) was performed, using a prerecorded speedboat signal input (twin-engine speedboat passing over a hydrophone submerged approximately $1 \mathrm{~m}$ under the surface in shallow water) [24].

The signal waveform with normalized amplitudes and its spectrogram are shown in Figure 14a,b, respectively. The input signal is periodical, each period consisting of approximately 3 seconds of the passing speedboat, followed by around 3seconds of pause. The maximal input signal voltage was scaled from $2 \mathrm{mV}$ to $20 \mathrm{mV}$ peak-to-peak, in steps of $2 \mathrm{mV}$.

\subsection{Results}

The two sensor interfaces' comparison with the prerecorded speedboat signal input is shown in Figure 15.

The results show that the proposed sensor interface outperforms the previously developed one, being able to operate with signals around $5 \mathrm{mV}$ peak-to-peak, while the previously developed one required over $20 \mathrm{mV}$ peak-to-peak. The $1.5 \mathrm{mV} / \mathrm{mV}$ sensitivity of the proposed interface stems from the increased rectification efficiency provided by the switched inductor.

In addition to the mentioned improvements, it should also be noted that the proposed sensor interface has a power consumption of $3.31 \mu \mathrm{W}$ compared to $8.25 \mu \mathrm{W}$ consumed by the previously developed one, which represents a reduction of around $60 \%$. This means that replacing the previously developed interface with the interface proposed in this work, would either extend the sensor node life-time, or allow for more sensors with the same power budget, leading to increased event detection accuracy.

To conclude the demonstration of applicability of the proposed interface in low-power analog acoustic event detection, Table 2 shows a comparison of its functionality and power consumption to state-of-the-art similar interfaces. 


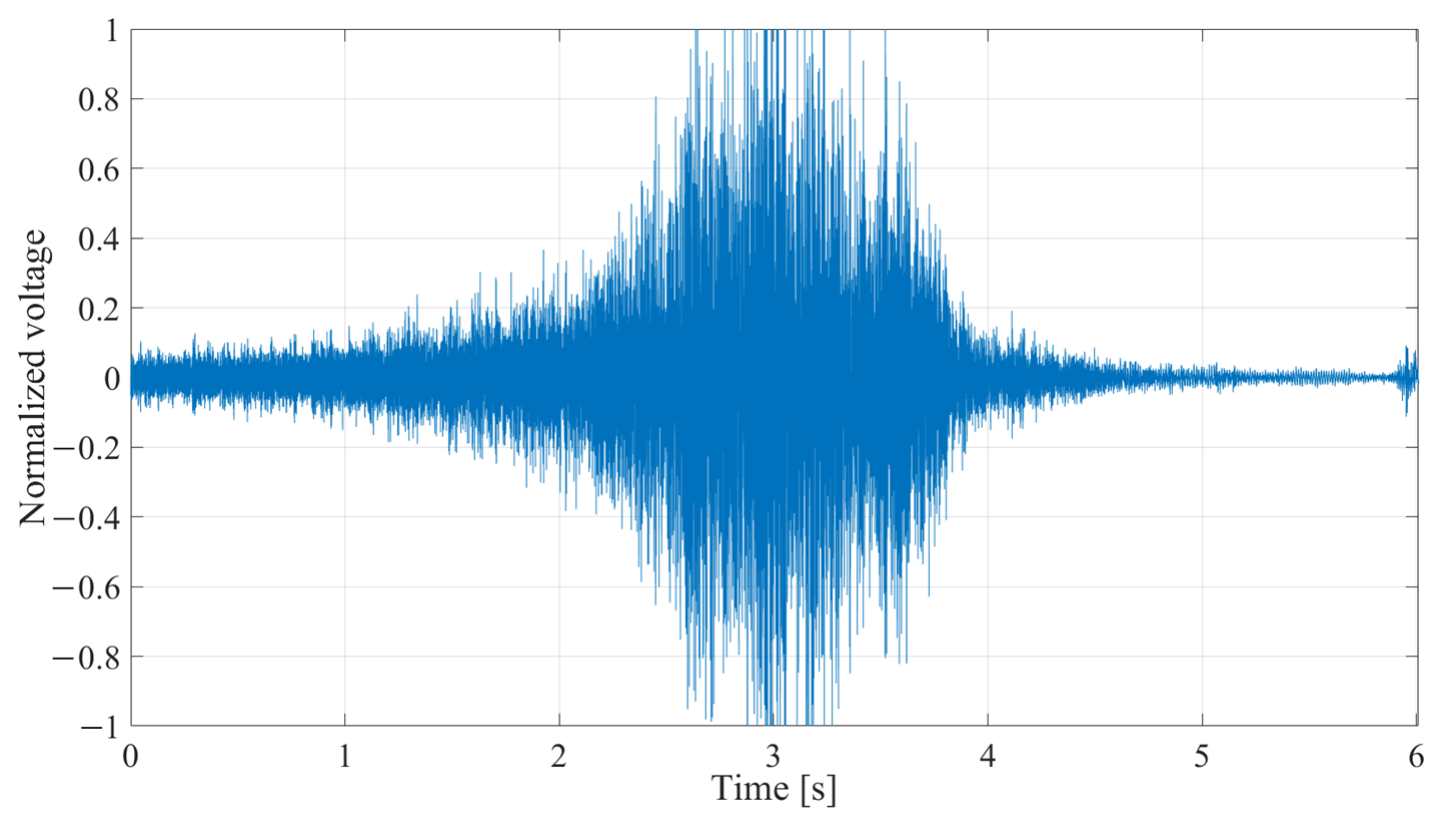

(a)

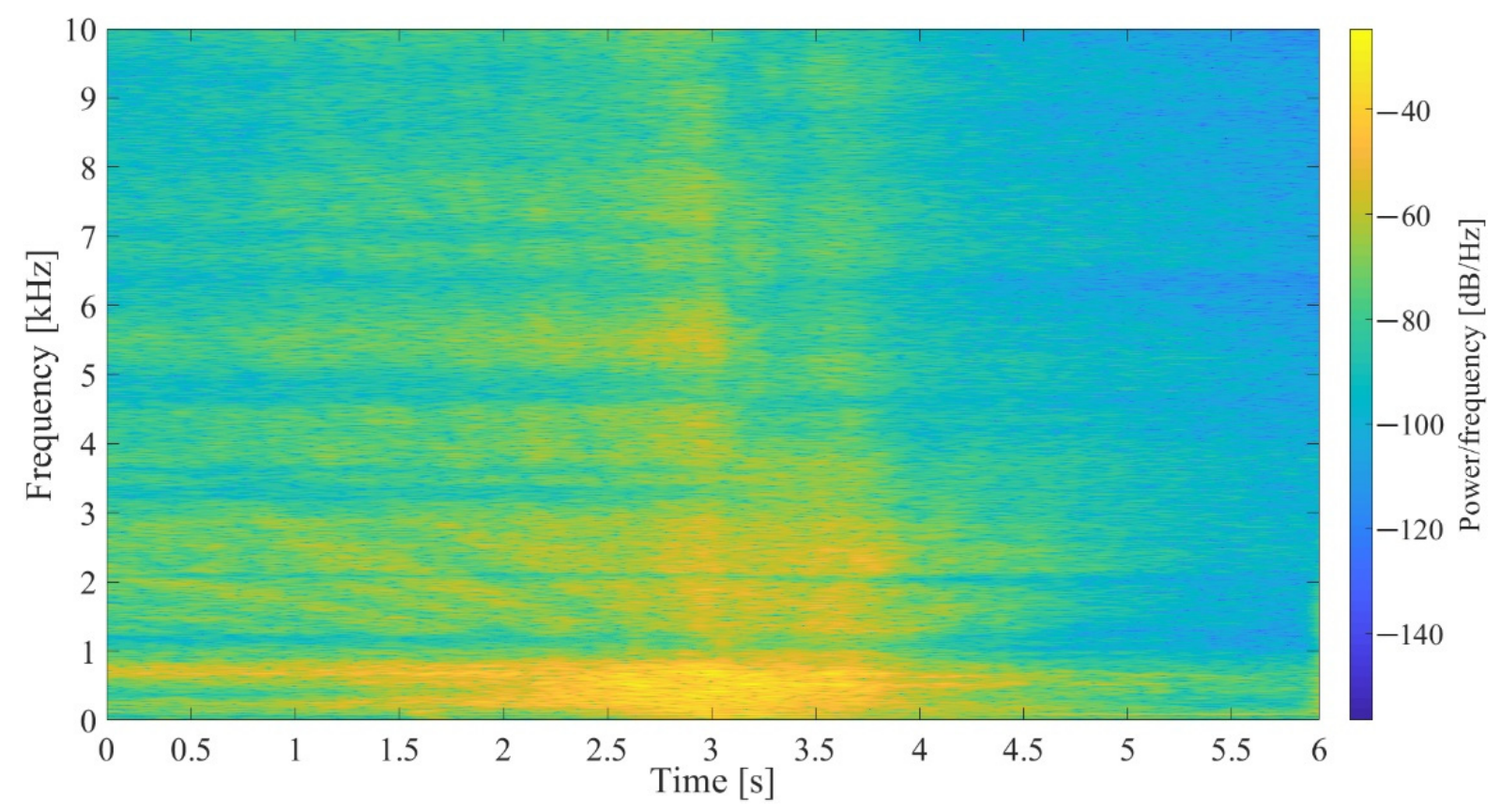

(b)

Figure 14. (a) Waveform of the prerecorded input signal, $V_{\text {in }}$, with a duration of approximately $3 \mathrm{~s}$, followed by around $3 \mathrm{~s}$ of pause. The voltage shown was normalized with regards to maximal value. (b) Spectrogram of the prerecorded input signal [18]. 


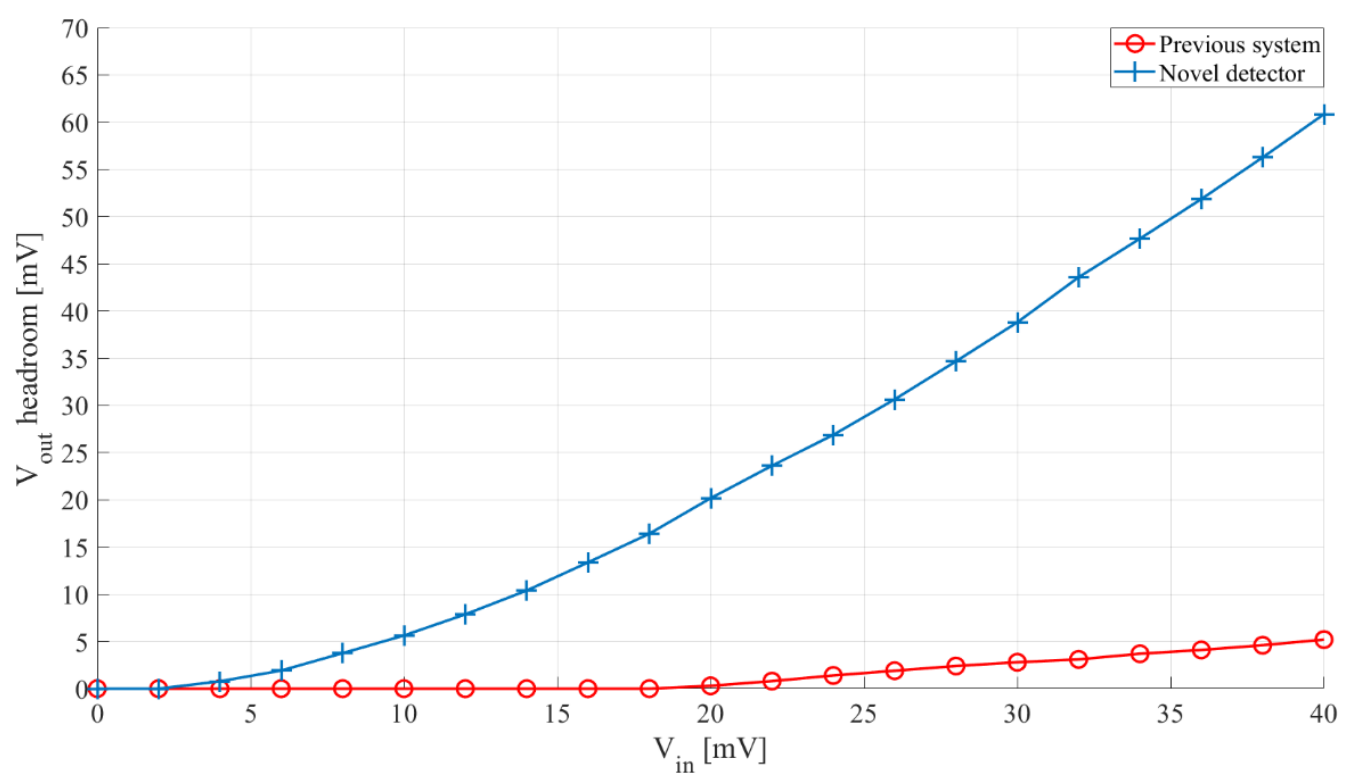

Figure 15. Comparison of outputs of the proposed sensor interface and one consisting of a bandpass filter and a passive voltage doubler. Input-prerecorded speedboat signal, $3 \mathrm{~s}$ of signal, $3 \mathrm{~s}$ of pause, scaled from $0 \mathrm{mV}$ peak-to-peak to $40 \mathrm{mV}$ peak-to-peak.

Table 2. Per channel power consumption comparison of state-of-the-art acoustic event detector sensor interfaces with the proposed interface.

\begin{tabular}{|c|c|c|c|}
\hline Reference & Technology & Functionality & Power Consumption $(\mu W)$ \\
\hline This work & Embedded design, COTSC & frequency decomposition and envelope detection & 3.31 \\
\hline [10] & Embedded design, COTSC & $\begin{array}{l}\text { frequency decomposition, envelope detection, } \\
\text { 1-bit quantization (adjustable) }\end{array}$ & 22.59 \\
\hline [9] & Embedded design, COTSC & $\begin{array}{l}\text { frequency decomposition, envelope detection, } \\
\text { 1-bit quantization (adjustable) }\end{array}$ & 11.52 \\
\hline [25] & Embedded design, COTSC & $\begin{array}{l}\text { frequency decomposition, amplification, } \\
\text { template matching (adjustable) }\end{array}$ & 9.32 \\
\hline [6] & Custom FPAA & $\begin{array}{l}\text { frequency decomposition, amplification, peak } \\
\text { detection, quantization, pattern recognition } \\
\text { (programmable) }\end{array}$ & 5.38 \\
\hline [26] & ASIC & $\begin{array}{c}\text { energy threshold detection, } 16 \text { feature extraction } \\
\text { based on amplification, filtering and absolute } \\
\text { value detection, and classification }\end{array}$ & 6 \\
\hline [27] & ASIC & $\begin{array}{l}\text { frequency decomposition, magnitude detection, } \\
\text { quantization, template matching }\end{array}$ & 2.92 \\
\hline
\end{tabular}

COTSC—commercial of-the-shelf components; FPAA—field-programmable analog array; ASIC—application specific integrated circuit.

\section{Conclusions}

Low-power analog sensors and interfaces present a necessity in IoT development. Following previous research on switched inductor filters and energy harvesters, a novel switched inductor frequency selective sensor interface is proposed. A simulation study was done to determine the key design parameters and characterize the interface performance with input signals up to $20 \mathrm{mV}$ peak-to-peak, at low acoustic frequencies from $100 \mathrm{~Hz}$ to $1 \mathrm{kHz}$. A prototype interface was developed and characterized, achieving the maximal sensitivity of approximately $2 \mathrm{mV} / \mathrm{mV}$ in the passband, four times lower sensitivity in the stopband, and a power consumption of approximately $3.31 \mu \mathrm{W}$. The novel sensor interface can operate with inputs around $5 \mathrm{mV}$ compared to over $20 \mathrm{mV}$ needed for 
the one consisting of an active bandpass filter and a passive voltage doubler, having around $60 \%$ lower power consumption $(3.31 \mu \mathrm{W}$ compared to $8.25 \mu \mathrm{W})$, thus enabling life-time extension or improved detection. The future work will focus on reconfigurable switched inductor sensor interfaces and lowering the power consumption of the switch control oscillator.

Author Contributions: Conceptualization, M.G. and V.B.; data curation, M.G.; investigation, M.G.; methodology, M.G. and V.B.; project administration, V.B.; supervision, V.B.; visualization, M.G.; writing-original draft, M.G. and V.B. Both authors have read and agreed to the published version of the manuscript.

Funding: Croatian Science Foundation, project: IP-2016-06-8379, SENSIRRIKA. Office of Naval Research Global, project: ONRG-NICOP-N62909-17-1-2160.

Institutional Review Board Statement: Not applicable.

Informed Consent Statement: Not applicable.

Data Availability Statement: Not applicable.

Acknowledgments: The work of the doctoral student Marko Gazivoda has been supported in part by the "Young researchers' career development project-training of doctoral students" of the Croatian Science Foundation funded by the European Union from the European Social Fund. This research has been supported in part by the U.S. Office of Naval Research Global under the project ONRG-NICOP-N62909-17-1-2160, AWAKE-ultra low power wake-up interfaces for autonomous robotic sensor networks in sea/subsea environments, and partially by Croatian Science Foundation under the project IP-2016-06-8379, SENSIRRIKA—advanced sensor systems for precision irrigation in karst landscape.

Conflicts of Interest: The authors declare no conflict of interest. The funders had no role in the design of the study; in the collection, analyses, or interpretation of data; in the writing of the manuscript, or in the decision to publish the results.

\section{References}

1. Kalsoom, T.; Ramzan, N.; Ahmed, S.; Ur-Rehman, M. Advances in Sensor Technologies in the Era of Smart Factory and Industry 4.0. Sensors 2020, 20, 6783. [CrossRef] [PubMed]

2. Zikria, Y.B.; Ali, R.; Afzal, M.K.; Kim, S.W. Next-Generation Internet of Things (IoT): Opportunities, Challenges, and Solutions. Sensors 2021, 21, 1174. [CrossRef] [PubMed]

3. Alioto, M. (Ed.) Enabling the Internet of Things; Springer International Publishing: Cham, Switzerland, 2017; pp. 1-45, ISBN 978-3319-51480-2.

4. Goux, N.; Badets, F. Review on Event-Driven Wake-Up Sensors for Ultra-Low Power Time-Domain Design. Midwest Symp. Circuits Syst. 2019, 554-557. [CrossRef]

5. Olsson, R.H.; Bogoslovov, R.B.; Gordon, C. Event Driven Persistent Sensing: Overcoming the Energy and Lifetime Limitations in Unattended Wireless Sensors. Proc. IEEE Sens. 2016, 1-3. [CrossRef]

6. Bhattacharyya, S.; Andryzcik, S.; Graham, D.W. An Acoustic Vehicle Detector and Classifier Using a Reconfigurable Analog/Mixed-Signal Platform. J. Low Power Electron. Appl. 2020, 10, 6. [CrossRef]

7. Mayer, P.; Magno, M.; Benini, L. A2Event: A Micro-Watt Programmable Frequency-Time Detector for Always-On Energy-Neutral Sensing. Sustain. Comput. Inform. Syst. 2019, 25, 100368. [CrossRef]

8. Jeong, S.; Chen, Y.; Jang, T.; Tsai, J.M.L.; Blaauw, D.; Kim, H.S.; Sylvester, D. Always-On 12-nW Acoustic Sensing and Object Recognition Microsystem for Unattended Ground Sensor Nodes. IEEE J. Solid-State Circuits 2018, 53, 261-274. [CrossRef]

9. Oletic, D.; Gazivoda, M.; Bilas, V. A Programmable 3-Channel Acoustic Wake-Up Interface Enabling Always-On Detection of Underwater Events Within 20 HA. In Proceedings of the Eurosensors 2018 Conference, Graz, Austria, 9-12 September 2018; pp. 1-7.

10. Mayer, P.; Magno, M.; Benini, L. Self-Sustaining Acoustic Sensor with Programmable Pattern Recognition for Underwater Monitoring. IEEE Trans. Instrum. Meas. 2019, 68, 2346-2355. [CrossRef]

11. Galante-Sempere, D.; Ramos-Valido, D.; Lalchand, K.S.; del Pino, J. Low-Power RFED Wake-Up Receiver Design for Low-Cost Wireless Sensor Network Applications. Sensors 2020, 20, 6406. [CrossRef] [PubMed]

12. Lu, S.; Boussaid, F. A Highly Efficient P-SSHI Rectifier for Piezoelectric Energy Harvesting. IEEE Trans. Power Electron. 2015, 30, 5364-5369. [CrossRef]

13. Wu, L.; Zhu, P.; Xie, M. A Self-Powered Hybrid SSHI Circuit with a Wide Operation Range for Piezoelectric Energy Harvesting. Sensors 2021, 21, 615. [CrossRef] [PubMed] 
14. Alex-Amor, A.; Moreno-Núñez, J.; Fernández-González, J.M.; Padilla, P.; Esteban, J. Parasitics Impact on the Performance of Rectifier Circuits in Sensing RF Energy Harvesting. Sensors 2019, 19, 4939. [CrossRef] [PubMed]

15. Gak, J.; Miguez, M.; Alvarez, E.; Arnaud, A. Integrated Ultra-Low Power Precision Rectifiers for Implantable Medical Devices. In Proceedings of the 2019 Argentine Conference on Electronics (CAE), Mar del Plata, Argentina, 14-15 March 2019; pp. 27-30. [CrossRef]

16. Trigona, C.; Giuffrida, S.; Andò, B.; Baglio, S.; Elettrica, I.; Doria, V.A. Micromachined “Random Mechanical Harvester on Inductor " to Recovery Energy from Very Low-Amplitude Vibrations with Zero-Voltage Threshold. In Proceedings of the 2016 IEEE SENSORS, Orlando, FL, USA, 30 October-3 November 2016; pp. 2-4. [CrossRef]

17. Gazivoda, M.; Oletic, D.; Bilas, V. Characterization and Comparison of Envelope Detectors for Wake-up Sensor Interfaces at Audio Frequencies. In Proceedings of the 2020 IEEE International Instrumentation and Measurement Technology Conference (I2MTC), Dubrovnik, Croatia, 25-28 May 2020; pp. 1-6. [CrossRef]

18. Gazivoda, M.; Oletić, D.; Trigona, C.; Bilas, V. Passive Extraction of Signal Feature Using a Rectifier with a Mechanically Switched Inductor for Low Power Acoustic Event Detection. Sensors 2020, 20, 5445. [CrossRef] [PubMed]

19. Argyrou, M.C.; Marouchos, C.C.; Darwish, M.; Iosif, E.; Paterakis, F. Investigation of the Switched Inductor Circuit for Harmonics Compensation. In Proceedings of the 2017 52nd International Universities Power Engineering Conference, UPEC 2017, Heraklion, Greece, 28-31 August 2017; Volume 2017, pp. 1-5. [CrossRef]

20. Marouchos, C.C. The Switching Function: Analysis of Power Electronic Circuits; The Institution of Engineering and Technology: London, UK, 2006; ISBN 0896038890.

21. Ott, H.W. Noise Reduction Techniques in Electronic Systems; Wiley-Interscience: Livingston, NJ, USA, 1988; ISBN 0-471-85068-3.

22. Ming, Y.; Ziping, C.; Jun, L. Characterization the Influences of Diodes to Piezoelectric Energy Harvester. Int. J. Smart Nano Mater. 2018, 9, 151-166. [CrossRef]

23. Thoen, B.; Ottoy, G.; Rosas, F.; Lauwereins, S.; Rajendran, S.; De Strycker, L.; Pollin, S.; Verhelst, M. Saving Energy in WSNs for Acoustic Surveillance Applications while Maintaining QoS. In Proceedings of the 2017 IEEE Sensors Applications Symposium (SAS), Glassboro, NJ, USA, 13-15 March 2017; pp. 1-6. [CrossRef]

24. Underwater Video of Twin Engine Boat Props High Speed. Available online: https://www.youtube.com/watch?v=6uQ7 IDqbmAE (accessed on 7 June 2018).

25. Sutton, F.; Da Forno, R.; Gschwend, D.; Gsell, T.; Lim, R.; Beutel, J.; Thiele, L. The Design of a Responsive and Energy-efficient Event-triggered Wireless Sensing System. In Proceedings of the 2017 International Conference on Embedded Wireless Systems and Networks, Uppsala, Sweden, 20-22 February 2017; pp. 144-155, ISBN 978-0-9949886-1-4.

26. Badami, K.M.H.; Lauwereins, S.; Meert, W.; Verhelst, M. A 90 nm CMOS, $6 \mu$ W Power-Proportional Acoustic Sensing Frontend for Voice Activity Detection. IEEE J. Solid-State Circuits 2016, 51, 291-302. [CrossRef]

27. Rumberg, B.; Graham, D.W.; Kulathumani, V. A Low-Power, Programmable Analog Event Detector for Resource-Constrained Sensing Systems. In Proceedings of the 2012 IEEE 55th International Midwest Symposium on Circuits and Systems (MWSCAS), Boise, ID, USA, 5-8 August 2012; pp. 338-341. [CrossRef] 